\title{
Seismic-attribute identification of brittle and TOC-rich zones within the Eagle Ford Shale, Dimmit County, South Texas
}

\author{
Osareni Ogiesoba · Ursula Hammes
}

Received: 5 August 2013/Accepted: 24 January 2014/Published online: 15 February 2014

(C) The Author(s) 2014. This article is published with open access at Springerlink.com

\begin{abstract}
Analysis of 3D poststack seismic attributes can be used to identify areas of high exploration potential within shale resource plays. We integrated seismic attributes and acoustic impedance (AI) with wireline logs to determine total organic carbon (TOC) distribution within the Eagle Ford Shale in South Texas. We computed TOC from wireline logs using the $\Delta \log R$ method and then used seismic attributes to predict TOC and deep-resistivity log distribution, and identify brittle zones within the seismic survey. Our results show that high-TOC and high-resistivity zones are laterally more continuous in the south part of the survey. In the north, continuity of these properties is broken by NE-SW-trending faults having throws ranging from about 10 to $100 \mathrm{ft}$ (3-30 m). High resistivity occurs in high-quality-factor $(Q)$ attribute zones. Although the relationship is nonlinear, resistivity and TOC increase as $Q$ increases. That is, both properties increase with increasing bed resistance suggesting increasing carbonate. Two high-resistivity zones, an upper resistive bed and a lower resistive bed, are identified within the Eagle Ford Shale. Additionally, because a strong positive linear relationship exists between $\mathrm{AI}$ and $Q, Q$ can be used to identify brittle zones. Compared to other attributes used in identification of brittle zones, $Q$ is faster and cheaper to compute from 3D poststack seismic data. Therefore, $Q$ could serve as a quicker, alternate method of identifying brittle zones within the Eagle Ford Shale.
\end{abstract}

Keywords Inversion - TOC - Resistivity - Brittleness . Faults · Attributes

O. Ogiesoba $(\bowtie) \cdot$ U. Hammes

Bureau of Economic Geology, Jackson School of Geosciences,

The University of Texas at Austin, Austin, USA

e-mail: osareni.ogiesoba@beg.utexas.edu

\section{Introduction}

The Cretaceous Eagle Ford Shale in South Texas is one of the most prolific shale resource plays in the United States. Covering an area of more than $11,000 \mathrm{mi}^{2}$ $\left(\sim 28,160 \mathrm{~km}^{2}\right)$ (Treadgold et al. 2011), it stretches from the East Texas basin, which is bordered by the Sabine uplift in the NE, across the San Marcos arch, to the Maverick Basin in the SW (Hentz and Ruppel 2011) (Fig. 1a). The study area is located in the SW corner of the productive trend (Fig. 1a). Since the Eagle Ford Shale was recognized as a major gas shale play in 2008, exploration there has been geared toward delineating fault-related fracture zones, as well as stratigraphic layers having abundant minor faults and brittle zones, to find the most productive intervals (Kuich 1989; Treadgold et al. 2011). Advances in horizontal-well construction and hydraulic stimulation have made it possible to generate fractures in rocks that would enable fluid migration into the well bore, thereby transforming shale-gas resources into economic reserves (Rickman et al. 2008; Sondergeld et al. 2010). The success or failure of hydraulic stimulation, however, depends on our ability to accurately identify and delineate brittle and ductile zones (Laubach et al. 2009) within the shale-gas interval. Brittle zones are those rock layers characterized by high velocity-that is, high Young's modulus-whereas ductile zones are layers characterized by low velocity-that is, low Young's modulus (Koesoemadinata et al. 2011; Sena et al. 2011). In this regard, seismic technology has been employed successfully through amplitude-versus-offset (AVO) inversion, which computes elastic properties-the $\lambda \mu$ and $\mu \rho$ attributes (where $\lambda$ and $\mu$ are Lamé's constants and $\rho$ is density) used to determine brittleness of the rock (Goodway et al. 1998; Koesoemadinata et al. 2011; Sena 
(a)

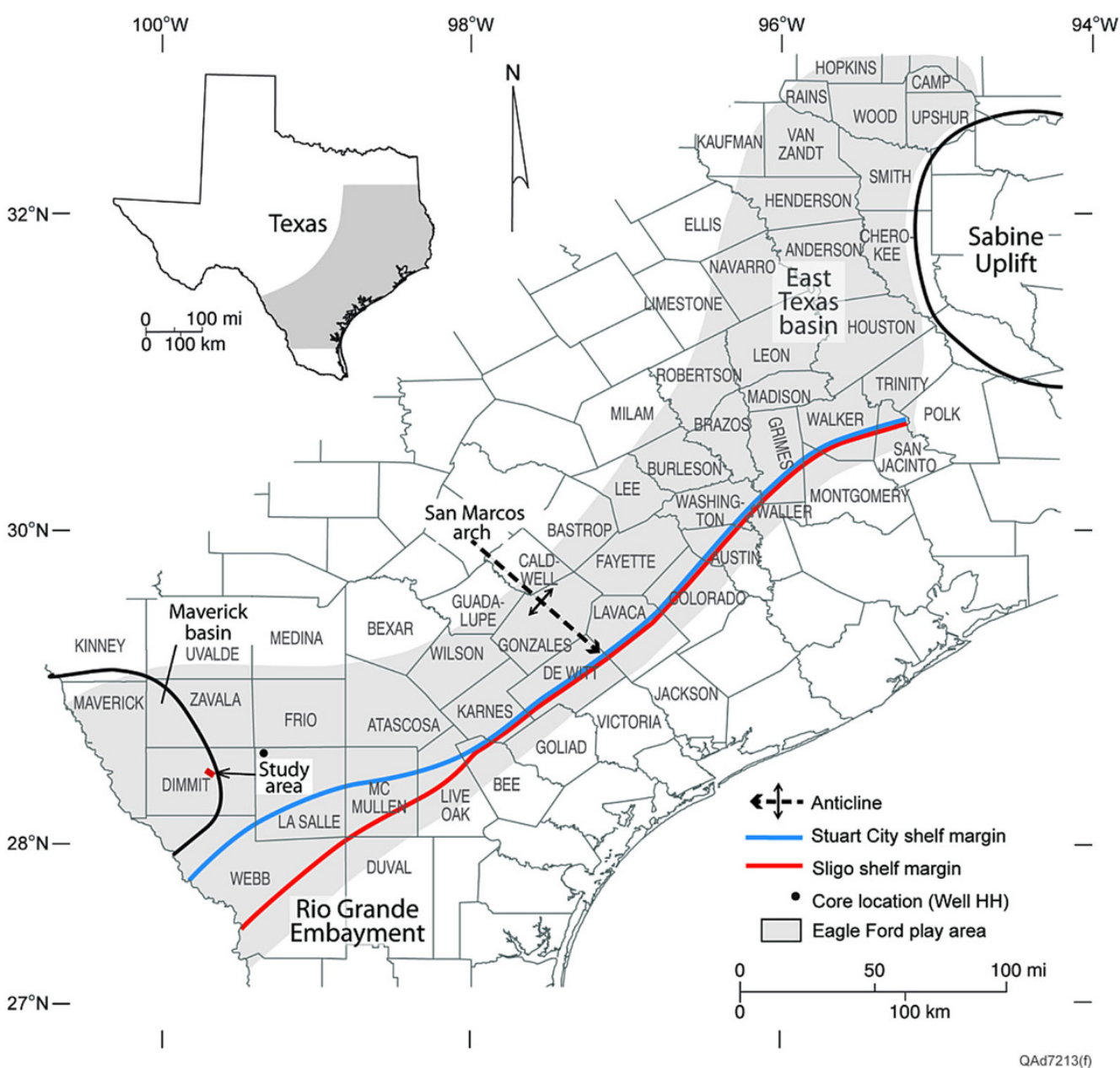

(b)

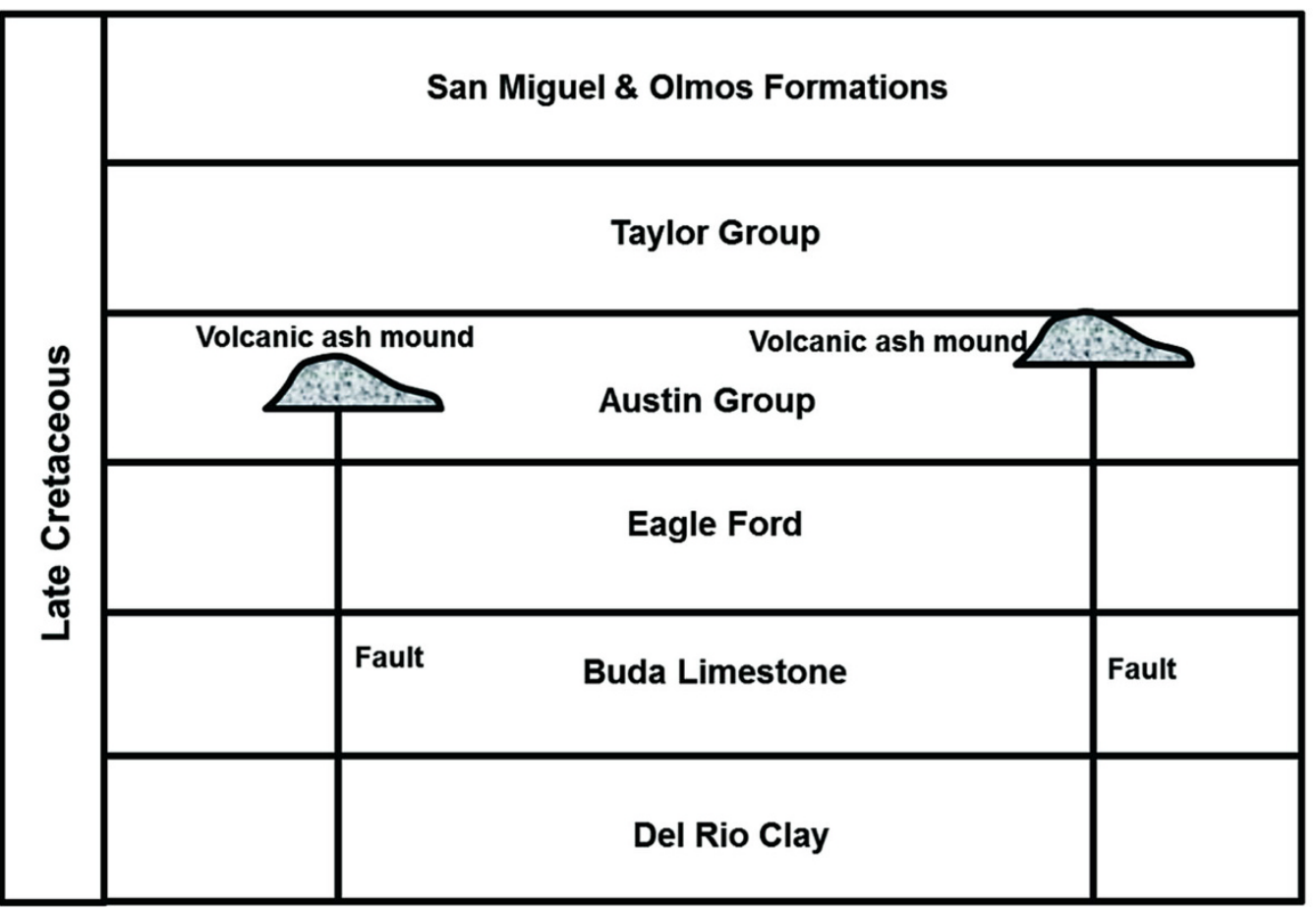


4Fig. 1 a Map showing areal extent of Eagle Ford Shale play in South Texas and location of study area (red box). Figure modified from Hentz and Ruppel (2011). b Schematic diagram showing stratigraphic succession in South Texas during Late Cretaceous

et al. 2011; Treadgold et al. 2011). This method requires a prestack data set that meets special AVO requirements.

Because quality and prolificacy of shale resource plays depend on the richness and maturity of the shale, areas having high total organic carbon (TOC) typically yield the best production (e.g., Hill et al. 2007; Hammes et al. 2011). Matching high-TOC-bearing zones with fracture clusters might provide a clue to increased productivity in these areas. Therefore, it is necessary not only to delineate fracture zones but also to determine TOC distribution within the survey area and to identify those fracture zones that are located within high-TOC zones. Three methods can be used to detect TOC concentration within a rock interval:
(1) measurement of TOC from core taken from the well bore, (2) computation of TOC from wireline logs using the $\Delta \log R$ method (Passey et al. 1990), and (3) calculation of TOC and lithology using the Multi Min method (Eastwood and Hammes 2010). The $\Delta \log R$ method (where $R$ is resistivity) yields results of log-calculated TOC in reasonable agreement with limited core measurements (Fig. 2). For example, the maximum deviations in TOC values between the two methods occur at depths of 6,870 , 6,990, and 7,300 ft $(2,094,2,130$, and 2,224 m), being $\sim 2$, $\sim 1$, and $1.5 \%$, respectively. At these depths, core-measured TOC values are $\sim 1, \sim 3.4$, and $\sim 2 \%$, whereas the corresponding log-calculated TOC values are $\sim 3,2.4$, and $0.5 \%$, respectively. Apart from these differences, the difference between core-measured and log-calculated TOC values at other depths is either 0 or $<1 \%$ (Fig. 2). Although these methods can provide TOC values, their

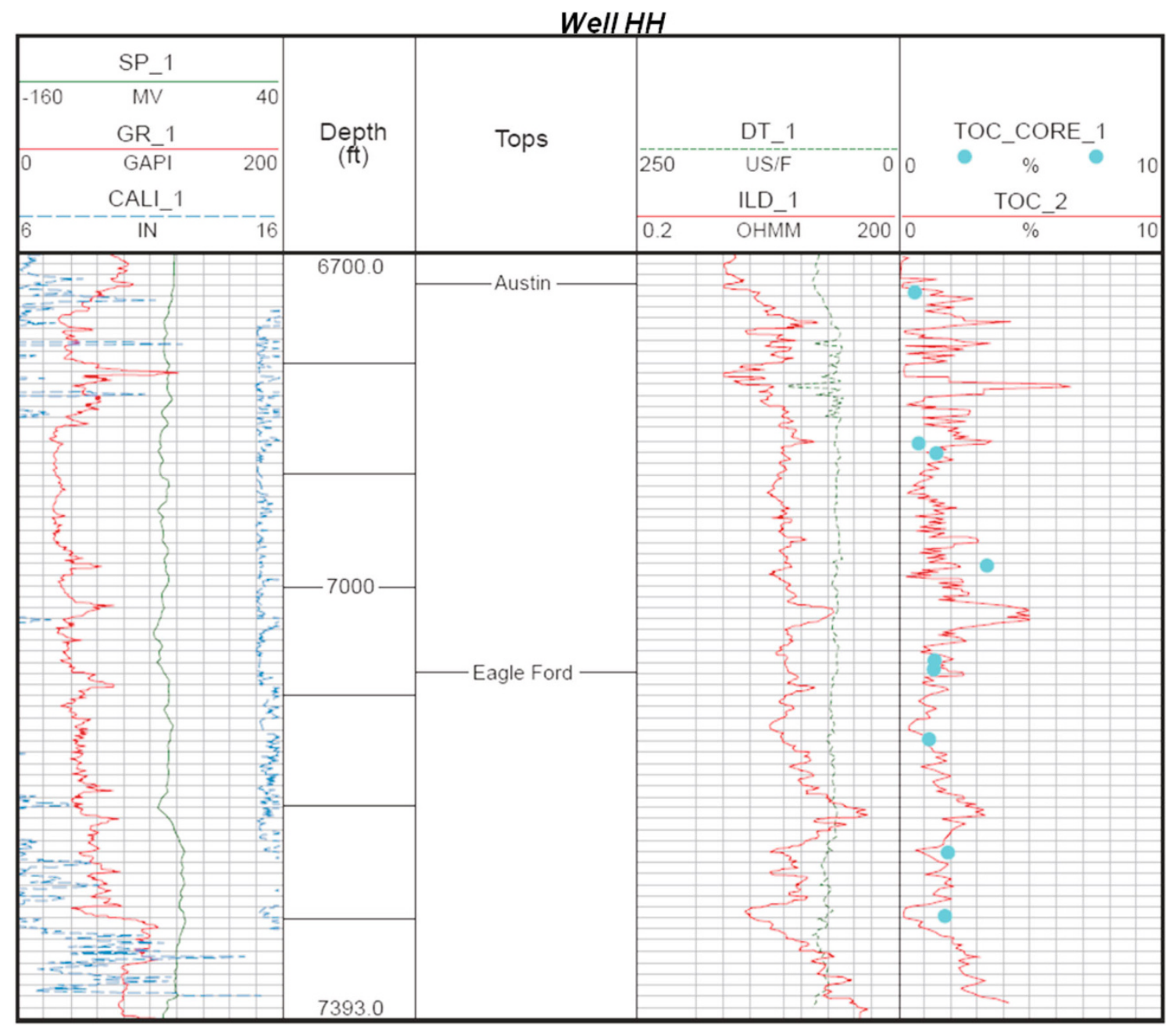

Fig. 2 Comparison between total organic carbon (TOC) computed using $\Delta \log R$ method and measurement from core in well $\mathrm{HH}$ (last track in figure). TOC measurements from core $=$ blue, TOC log derived from $\Delta \log R$ method $=$ red. Note reasonable agreement between methods. Maximum difference between two methods $\sim 2 \%$ at depth of $6,870 \mathrm{ft}$ but $\leq 1.5 \%$ at all other depths (see text for details). First track shows gamma-ray (red), spontaneous-potential (green), and caliper (blue) logs; second track shows sonic (green) and resistivity (deep induction) (red) logs

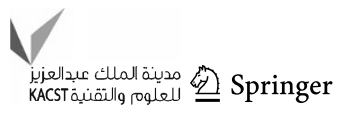


application is limited to well bore locations. In order to analyze TOC away from the well bore and characterize TOC throughout the entire seismic 3D volume, alternate methods are necessary.

In the subsurface, fractures are not easily identified. However, it is possible to identify the rock intervals in which fractures are most likely to occur. These intervals are composed of brittle rock characterized by relatively higher Young's modulus, higher velocity, higher AI, and higher $Q$ than the surrounding, more ductile rock. At this juncture, 3D seismic method seems to be the best technology to employ because these physical properties of the rock can be derived at many hundreds of closely spaced locations [e.g., $82 \mathrm{ft}(25-\mathrm{m})$ spacing] within a 3D survey area (Hampson et al. 2001; Ogiesoba 2010). This method not only offers interpreters a way of viewing lateral distribution of the rock physical property but also enables the volumetric computation of that physical property. In this paper, we adopt an integrated approach by combining results from petrophysical analysis with seismic attributes to determine brittle zones, TOC, and resistivity distributions within a 3D survey located in Dimmit County, South Texas.

\section{Geological background and project objectives}

The Eagle Ford Shale of South Texas, late Cenomanian to Turonian in age, is underlain by the lower Cenomanian Buda Limestone and overlain by the Coniacian to Santonian Austin Chalk (Fig. 1b). The Buda Limestone acts as a distinctive seismic marker bed throughout the areal extent of the Eagle Ford Shale, the Eagle Ford Shale ranging from less than 40 to $400 \mathrm{ft}(\sim 12-122 \mathrm{~m})$ in thickness. Thickness correlates with onlap and truncation of unconformities on the top and bottom of the Eagle Ford across the depositional area from the Maverick Basin in the south to the East Texas basin in the north (Donovan and Staerker 2010; Fig. 1a). In the study area, thickness is fairly uniform at about $310 \mathrm{ft}(\sim 95 \mathrm{~m})$. The Eagle Ford was deposited during a worldwide second-order transgression, and deposition of organic-rich marine shales above the Buda Limestone formed the organic-rich lower Eagle Ford Shale (Dawson 2000; Hentz and Ruppel 2011; Treadgold et al. 2011). A major condensed section occurs within the Eagle Ford Shale, separating the upper member of the Eagle Ford that composes the highstand sequence (Dawson 2000; Donovan and Staerker 2010). Whereas the lower Eagle Ford unit is characterized by dark, laminated shales, the upper, regressive unit consists of thinly intercalated shales, limestones, and carbonaceous, quartzose siltstones (Dawson 2000). Smaller scale cycles are recorded by intercalated, thin, carbonate-rich layers containing marine organic-rich shales. The Eagle Ford, bound by sequence boundaries at its base and top, comprises one complete depositional sequence, Eagle Ford strata being unconformably overlain by the Austin Chalk (Grabowski 1981). Overlying the Austin Chalk is the Taylor Group, which is composed primarily of shale; San Miguel and Olmos sands overlie the Taylor Group.

Deposition of the Upper Cretaceous formations was accompanied by volcanic eruptions, during which volcaniclastic rocks were interlayered with formations such as the Cenomanian Del Rio Clay (Baldwin and Adams 1971; Ewing and Caran 1982). Ewing and Caran (1982) found that the magma came through NE-SW-oriented, strike-slip, vertical to subvertical regional faults. The period of magmatism continued throughout deposition of the Austin Chalk and was at its peak during Austin-Taylor deposition, particularly in the Maverick Basin in the SW (Spencer 1969; Ewing and Caran 1982). As eruptions continued, the magma built volcanic islands that created platforms for the deposition of shallow-water carbonates having good porosity (Luttrell 1977). Because of intense seawater diagenesis, the magma cones were altered into permeable and porous palagonite. Overlying the Austin Chalk is the Taylor Group, which is primarily composed of shale rich in organic matter from the sea transgressing yet again (Ewing and Caran 1982). Finally, with the recession of the sea, the San Miguel and Olmos Formations were deposited over the Taylor Group.

Two main conventional hydrocarbon plays lie within these stratigraphic units: (1) a structural play within the San Miguel and Olmos Formations and (2) a stratigraphic play within the porous palagonite and porous shallow-water carbonate (Austin Chalk) (Lewis 1977; Ewing and Caran 1982). The Eagle Ford Shale was recently recognized as a major unconventional resource play having gas, condensate, and oil potential. The shale interval is actively being exploited, and 3,000 wells were drilled between 2009 and 2012 (IHS Energy Information 2012).

A typical seismic line within the survey showing several features is displayed along transect A-A' (Fig. 3a). Shown in this figure are two sets of NE-SW trending faults: (1) the almost- $45^{\circ}$-dip-angle faults (black) and (2) the subvertical to vertical faults (red) cutting the top Del Rio. In some cases, the subvertical faults (red) cut into the Austin Chalk, intersecting the black-colored faults. In the coherency transect (Fig. 3b), several faults can be seen within the Taylor Group that did not penetrate the Austin Chalk below. Numerous small faults, as well as two major faults, can be seen in the interval between the top Austin Chalk and top Edwards (Fig. 3b). Whereas weak faults are located mostly in the SE, major faults, particularly two that cut through the Edwards into the Austin Chalk, are located in 
Fig. 3 a Typical seismic section A-A' through Well D, showing interpreted

stratigraphic surfaces and faults. Note vertical to subvertical faults (red) having predominantly SE throw direction and faults (black) having NW throw direction. b Corresponding coherency section showing two prominent major faults that cut the Del Rio into the Austin Chalk and other small faults. Light brown in coherency section indicates areas of high coherence; darkblue vertical and subvertical stripes are faults. Weak faults having small displacements are represented by white vertical-tosubvertical stripes. AC Austin Chalk, $T G$ Taylor Group, $U E$ upper Eagle Ford, $M H$ mapped horizon, $L E$ lower Eagle Ford, $B D$ Buda, $D R$ Del Rio. Area in yellow is entire Eagle Ford interval. Red log curve sonic; black log curve gamma ray. On sonic curve, deflections to right $=$ increasing interval velocity; deflections to left $=$ decreasing interval velocity. On gamma-ray curve, deflections to

right $=$ increasing gamma ray; deflections to left $=$ decreasing gamma ray. $T W T$ two-way time. Definitions of these

abbreviations, as well as area in yellow, apply to all other figures

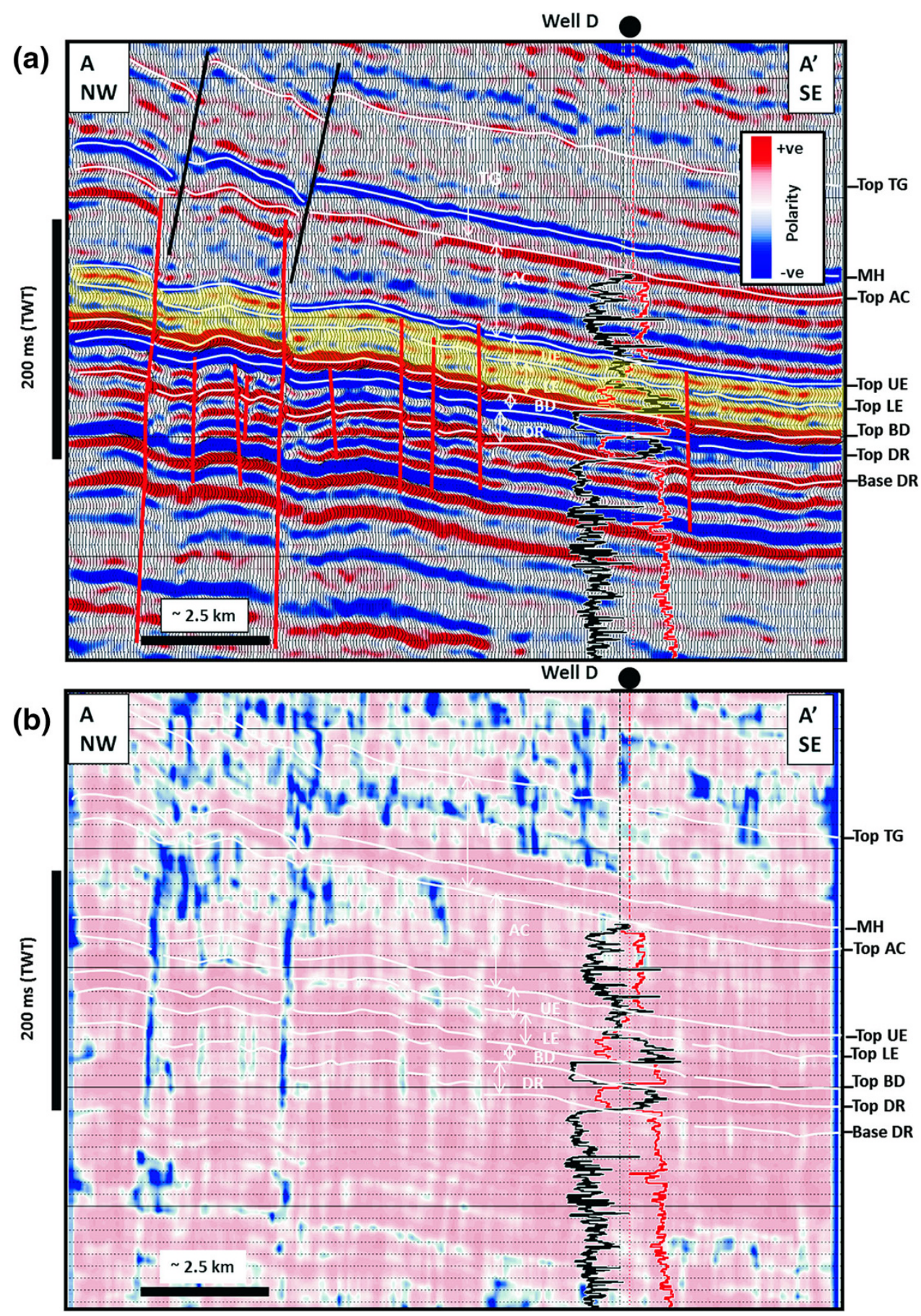

the NW. Note the downthrown direction of these two sets of faults. Whereas the black-colored faults are downthrown to the NW, the red-colored faults are downthrown to the SE (Fig. 3a). The Eagle Ford Shale interval (yellow zone) is about $310 \mathrm{ft}(\sim 95 \mathrm{~m})$ thick. Given the foregoing geologic scenario, our objective was to use the existing well database in conjunction with seismic attributes to identify the high-resistivity and TOC-rich zones within the Austin Chalk and Eagle Ford that could be used to augment hydrocarbon exploration.

\section{Methodology and database}

Our database consists of a 3D seismic survey covering a $32-\mathrm{mi}^{2}$ area $\left(\sim 82 \mathrm{~km}^{2}\right)$. The stacking bin size is $34 \times 34 \mathrm{~m}$, and the sampling interval during acquisition was $2 \mathrm{~ms}$. The well database is composed of six wells (Fig. 4a). Shown on the base map are three seismic traverses, A-A', B-B', and C-C'. The method of study is an integrated workflow in which we first conducted a petrophysical analysis to determine TOC. A well-to-seismic tie 
Fig. 4 a Base map of study area displaying three seismic traverses and well locations discussed in paper. b Seismic section B-B' showing well seismic tie at Well A. Note dominant fault-throw direction of red faults is NW, in contrast to those in section A-A'. Yellow curve synthetic seismogram

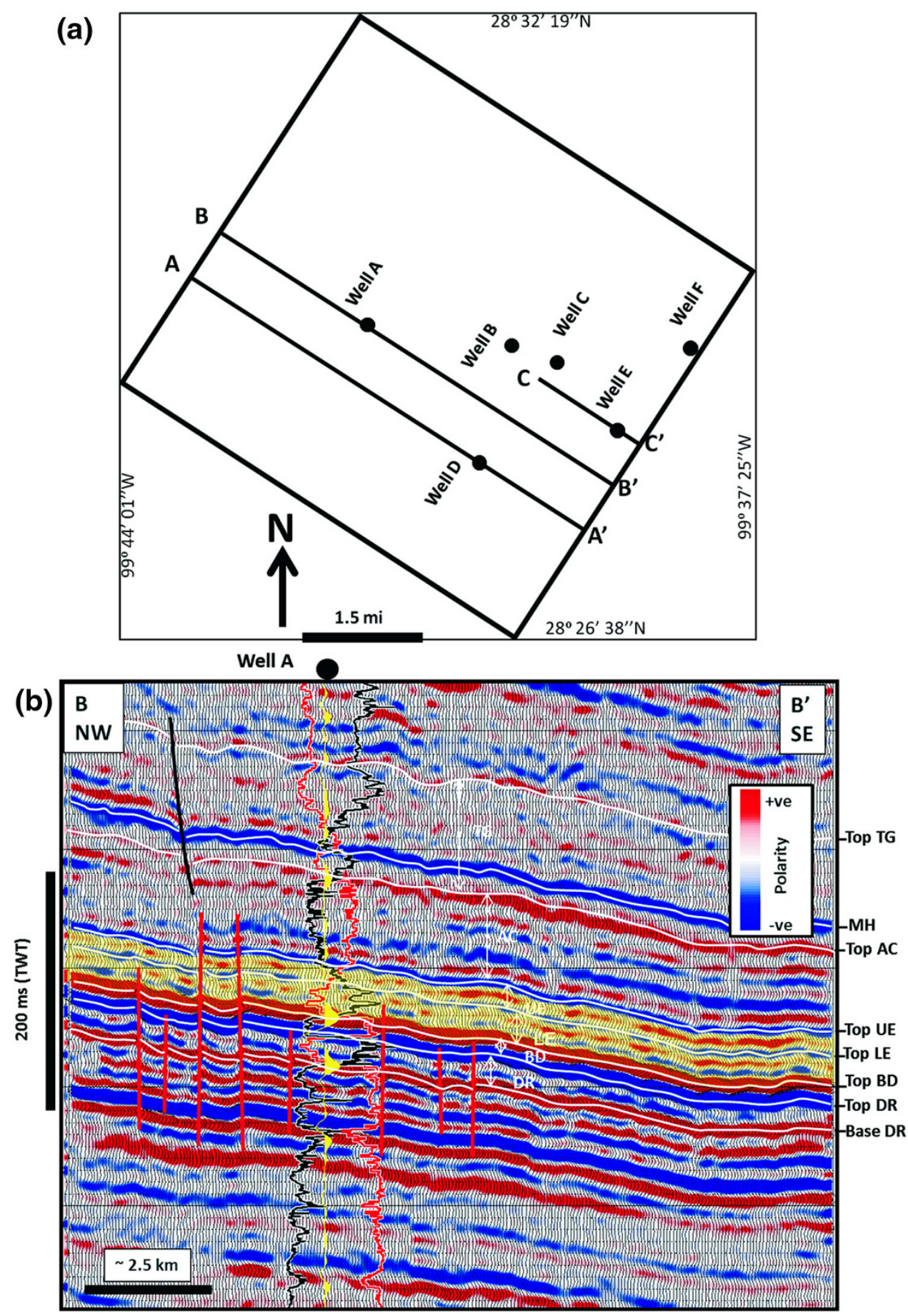

was established through a synthetic seismogram (Fig. 4b) to identify key stratigraphic surfaces that we later interpreted to generate horizon maps. Note the strong amplitude reflection associated with the top Buda (base Eagle Ford) (Fig. 4b). This strong character enabled identification of the base Eagle Ford throughout the survey. In addition, note that in seismic transect B-B', the dominant fault-throw direction of the faults at base Eagle Ford Shale (red) is NW, whereas the fault-throw direction of faults within the Austin
Chalk (black) is SE. Fault-throw directions in this transect are in contrast with those seen along transect A-A' (Fig. 3b), where the faults at base Eagle Ford Shale (red) are downthrown to the SE and the faults within the Austin Chalk (black) are downthrown to the NW. Furthermore, the thickness of the Eagle Ford Shale interval (yellow zone) at Well A is approximately the same as that at Well D-about $310 \mathrm{ft}(\sim 95 \mathrm{~m})$. Generated horizons maps, together with necessary log properties, were used in acoustic-impedance 
(AI) inversion. Results from AI, horizons maps, and seismic attributes computed from 3D poststack data were input into an industry-standard multiattribute analysis algorithm to predict gamma ray (lithology), TOC, and resistivity (deep induction log) using the multiattribute algorithm. The procedure involved has been described by Hampson et al. (2001), Ogiesoba (2010) and Ogiesoba and Eastwood (2013). As such, it will not be repeated in this paper. It is sufficient to say that the choice of the optimal number of attributes used in the prediction process is determined by the algorithm from the plot of mean squared error between the predicted and actual log property versus the number of attributes. The number of attributes where the error convincingly stops decreasing is taken as the optimal number of attributes. This plot is demonstrated under the result section in this paper.

Because quality factor $Q$ featured prominently in the prediction of TOC and resistivity, we closely examined the use of $Q$ in seismic interpretation. By definition, $Q$ is a transmissive attribute, similar to instantaneous and interval velocities; it indicates relative absorptive characteristics of bedrocks (Johnston et al. 1979; Toksoz et al. 1979; Johnston and Toksoz 1981). The attribute has a strong relationship with porosity, permeability, and fractures (Johnston et al. 1979; Robinson and Treitel 2008). High-porosity rocks are more absorptive and are generally characterized by low $Q$, whereas low-porosity (more compacted, high-velocity) rocks are less absorptive and are characterized by high $Q$ (Hamilton 1972a, b; Toksoz et al. 1979; Johnston and Toksoz 1981). Fault zones, having high porosity and permeability, are characterized by low $Q$. Because highvelocity rocks have higher $Q$ values, $Q$ also indicates the relative Young's modulus of the rock. That is, high $Q$ suggests high Young's modulus, and low $Q$ suggests low Young's modulus (Hamilton 1972b; Johnston et al. 1979; Johnston and Toksoz 1981). The $Q$ attribute was computed according to the following expression (Barnes 1992):

$Q(t)=\frac{\pi f(t)}{\frac{\mathrm{d}}{\mathrm{d} t}\left(\log _{\mathrm{e}} A(t)\right)}$

using a 50-m sliding window. In Eq. 1, $A(t)$ is instantaneous amplitude (amplitude envelope), and $f(t)$ is instantaneous frequency. Further simplification shows the denominator on the right-hand side of Eq. 1 to be the derivative of the amplitude envelope divided by the envelope, suggesting the energy-decay rate (Barnes 1992, 1993).

Seismic attribute rock property prediction-conceptual review

Before resistivity and TOC prediction using seismic attributes and well log data are discussed, pertinent rock physical properties pertaining to resistivity and P-wave velocity need to be examined. As documented in the literature (e.g., Grant and West 1965), the electrical conductivity exhibited by a rock depends on its permeability and porosity and on the conductivity of the fluids that it contains, rather than on its mineralogical composition. Grant and West (1965) discussed a relationship between resistivity and porosity and saturation for sedimentary rocks (sandstones and carbonates), given as.

Resistivity $\rho=I F \rho_{\mathrm{w}}$,

where $I$ is resistivity index, $F$ is formation factor, and $\rho_{\mathrm{w}}$ is resistivity of water in the formation. Formation factor $F$ depends on porosity and is given as

$F=a \varphi^{-m}$,

where $\varphi$ is porosity of the rock and $a$ and $m$ are positive constants. From Eqs. 2, 3, resistivity can be seen to be higher for denser and more compact rocks, such as dense limestone. That is, rocks having high AI (high velocity) have high resistivity. However, if such compact rock contains pockets of clay having formation water, overall resistivity is decreased. Note that fluid content is emphasized.

Furthermore, Faust (1953) provided a relation linking seismic-wave (P-wave) velocity to resistivity of rocks, given as

$V=C L^{1 / 6} Z^{1 / 6}$,

where $C=2 \times 10^{3} ; L$ is lithology, a quantity proportional to formation resistivity; and $Z=$ depth of rock. Although this relationship was derived more than five decades years ago, it still sheds light on the possibility of predicting resistivity using seismic attributes. In Eq. 4, note that resistivity of rock increases as velocity increases (i.e., with increasing compactness). If the porous zone in a carbonate rock contains pockets of clay rich in TOC, or if the porous zone is filled with hydrocarbon, resistivity within that zone is increased because TOC or hydrocarbon does not conduct electricity. Because velocity can be derived as seismic waves propagate, waves traveling through a porous medium filled with hydrocarbon or TOC-rich clay will have slower velocity. In this case, the low velocity indicates increased porosity. As such, longer transit times are recorded in such a medium, and instantaneous frequencies are lower than the frequencies of the surrounding rocks (Ogiesoba and Eastwood 2013). This correlation suggests that seismic attributes, such as instantaneous frequencies, dominant frequencies, and other frequency-related and amplitude-related attributes (such as envelope, quality factor, etc.), can be employed to predict resistivity. Herein are the physical principles upon which resistivity and TOC prediction, by way of seismic attributes, are based. 


\section{Results}

Petrophysical analysis

The intent of the petrophysical study was to derive TOC $\log$ data at well locations that would be used in the mutiattribute prediction process (Fig. 5). The first track contains gamma-ray (GR), caliper (CALI), and spontaneous potential (SP) logs; the well bore is generally in gauge; and the GR response is generally 80-150 API. The second track contains the resistivity $\log$ (ILD) and sonic $\log$ (DT). Values for these logs range from about $4.3 \Omega \mathrm{m}$ in the Austin Chalk to more than $200 \Omega \mathrm{m}$ in places in the Eagle Ford Shale. This track also displays the separation of DT and ILD used in the manner of $\Delta \log R$ analysis (Passey

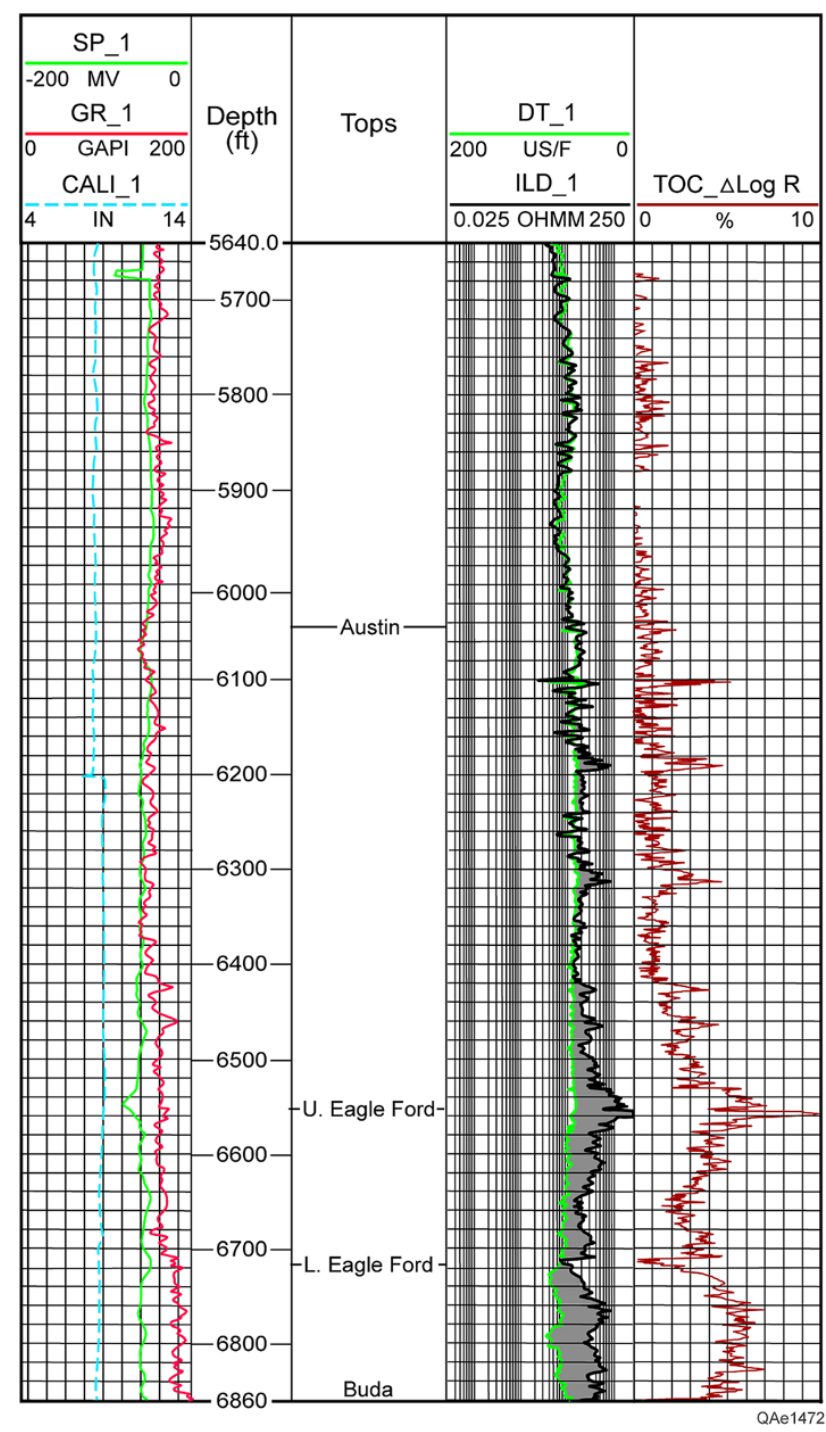

Fig. 5 Petrophysical analysis results showing derived total organic carbon (TOC) $\log$ (last track). All other tracks discussed in text. $L$. Eagle Ford lower Eagle Ford, U. Eagle Ford upper Eagle Ford et al. 1990); ILD is made to overlie DT, where low ILD values are seen. The logs overlie one another in the uppermost Eagle Ford and at the top of the lower Eagle Ford. The gray shading between DT and ILD indicates kerogen and/or hydrocarbons. This pair of logs was used to compute TOC because sonic logs are generally available for wells in this study. The TOC $\log$ that was computed using the $\Delta \log R$ method by employing the Passey et al. (1990, 2010) equation is displayed in the third track (in brown; Fig. 5), and limits range from 0 to $10 \%$. Calculated TOC values are in reasonable agreement with measured TOC values from a core taken from a nearby well (Fig. 2).

Seismic inversion-acoustic impedance

Results of AI inversion are now examined (Fig. 6). Along transect B-B' (Fig. 6a), AI results show that some variations in AI values, in both temporal and lateral directions, occur within the Austin Chalk, upper Eagle Ford, and lower Eagle Ford intervals. Note that the lowest AI values are in green and the highest are in magenta (see color bar). Cross plots between inverted and original AI (Fig. 6b) show a high degree of correlation, with a correlation coefficient of 0.99 . Note the wide variation in AI values. For example, between a time of 1,100 and 1,167 ms (67 ms interval), the AI spans from about 28,000-45,000 ft/s g/ $\mathrm{cm}^{3}$ (difference $=17,000 \mathrm{ft} / \mathrm{s} \mathrm{g} / \mathrm{cm}^{3}$ ). This relatively wide range in AI values within a relatively short interval of time shows that although the duration may be short, the interval can be composed of rocks having different facies. Close inspection of the lower Eagle Ford (Fig. 6a) shows that it can be subdivided into three units, and some stratigraphic interpretations can be deduced on the basis of the AI values. The lowermost unit at this location is $\sim 9 \mathrm{~m}$ thick; it is a highstand-transgressive marine shale (Treadgold et al. 2011; Slatt et al. 2012) having a low AI value that sits atop the Buda. This shale is followed by a layer of $\sim 8 \mathrm{~m}$ thick having higher AI values; it is probably richer in calcareous material. This second interval was most likely deposited during sea-level highstand (Grabowski 1981). Over this unit, a third layer $\sim 9 \mathrm{~m}$ thick composed of shale and having low AI values and rich organic matter was deposited when the sea transgressed the previously deposited Eagle Ford layers. Deposition of carbonate-rich rocks commenced again when the sea-level became highstand once more; however, the carbonate sediments intertongued with some shales owing to the interchange of highstand and transgressive processes. This unit, which has relatively higher AI values, constitutes the upper Eagle Ford (Fig. 6a). The unit grades into more carbonate-rich rock which was also deposited during a highstand of sea-levelthe Austin Chalk having high AI values (magenta, Fig. 6a). Finally, the sea transgressed yet again, leaving shale-rich 


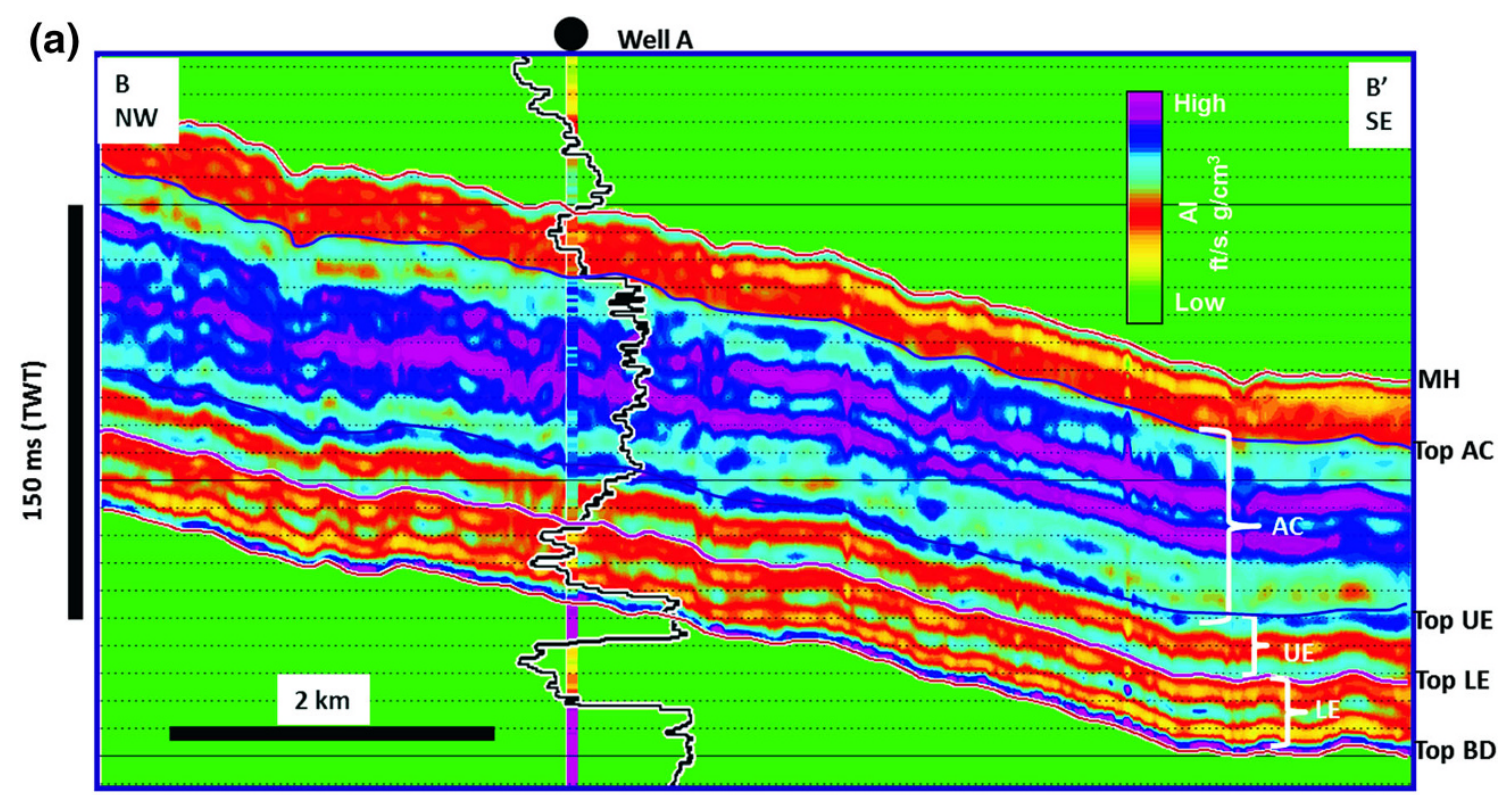

(b)

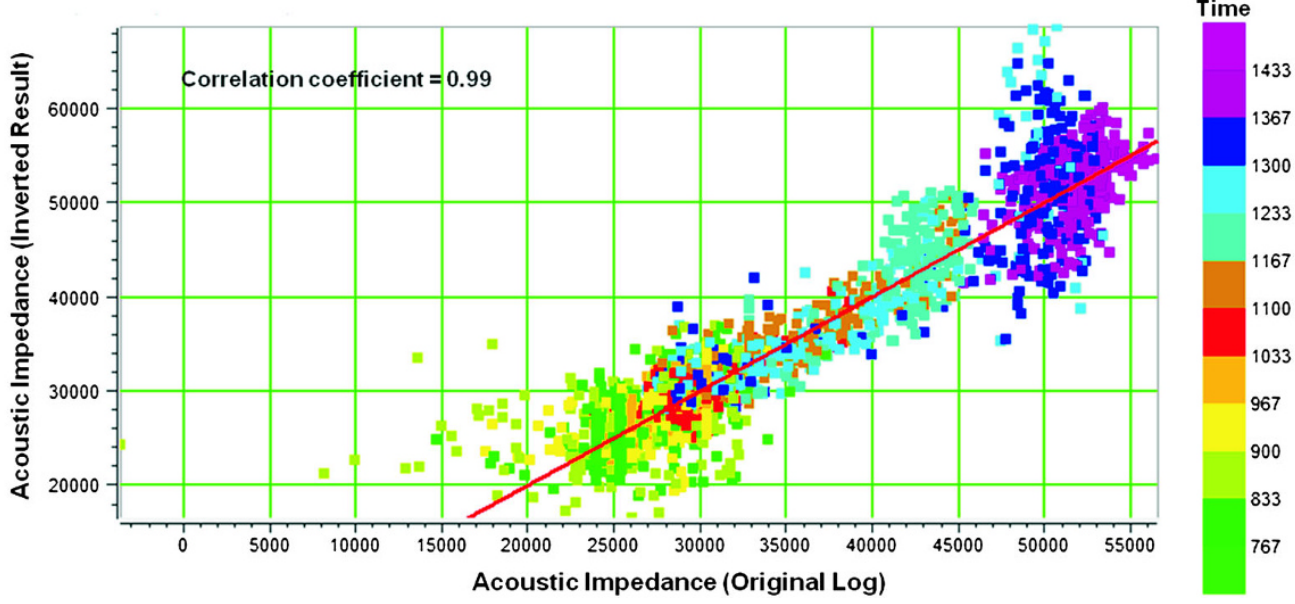

Fig. 6 Results from acoustic impedance (AI) inversion showing a vertical and lateral variations in AI along transect B-B'. b Cross plot of inverted versus original $\mathrm{AI}$ also showing vertical variations in $\mathrm{AI}$ (see text for discussion)

sediments having low AI (Grabowski 1981; Ewing and Caran 1982).

Prediction of gamma ray (lithology), TOC, and resistivity (deep induction $\log$ )

Using seismic attributes derived from the poststack data set, together with $\mathrm{AI}$ as an external attribute, we performed multiattribue analysis so as to predict the gamma ray. Because the gamma-ray log is used as the lithology log, predicting the gamma-ray log is considered equivalent to predicting lithology. From an array of computed poststack seismic attributes, the multiattribue analysis algorithm was used to select relevant attributes through a method of validation and testing (Hampson et al. 2001; Ogiesoba 2010).
Our intent was to obtain the distribution of shale-rich zones within the Eagle Ford interval throughout the survey area. Note that in the vertical distribution of gamma ray (lithology) (Fig. 7a), the lower Eagle Ford has the highest concentration of gamma ray. Because this interval on the $\mathrm{AI}$ transect corresponds to the lowest AI values, we conclude that it must be rich in organic materials. Gamma ray gradually decreases within the upper Eagle Ford and finally grades into low gamma ray in the Austin Chalk. Capping the Austin Chalk is an interval of moderately high gamma ray. We found the point at which the error stops decreasing to be at attribute \#3, suggesting that three attributes were sufficient to predict gamma ray having a correlation coefficient of 0.95 (Fig. 7b, c). Although the error decreased slightly at attribute \#4 and then starts to increase again at 
Fig. 7 Gamma-ray prediction showing a gamma-ray distribution along transect BB'. b Plot of average error versus number of attributes to determine optimal number of attributes to use in prediction processes. Note red curve is mean squared error between predicted and actual log property when a well is hidden and remaining wells together with number of attributes are used to predict log property; whereas black curve is mean squared error that is obtained when all wells together with number of attributes are used to predict $\log$ property. For example, if there are five wells, red curve is obtained when four wells are used at a time. That is, at every attribute combination, prediction is performed five times, each time hiding one well and previously hidden well is brought back into the prediction process; while black curve is obtained by using all five wells every time during the prediction process. For detained explanation, refer to Hampson et al. (2001) and Ogiesoba (2010). c Cross plot of actual gamma ray versus predicted gamma ray showing high correlation coefficient of 0.95

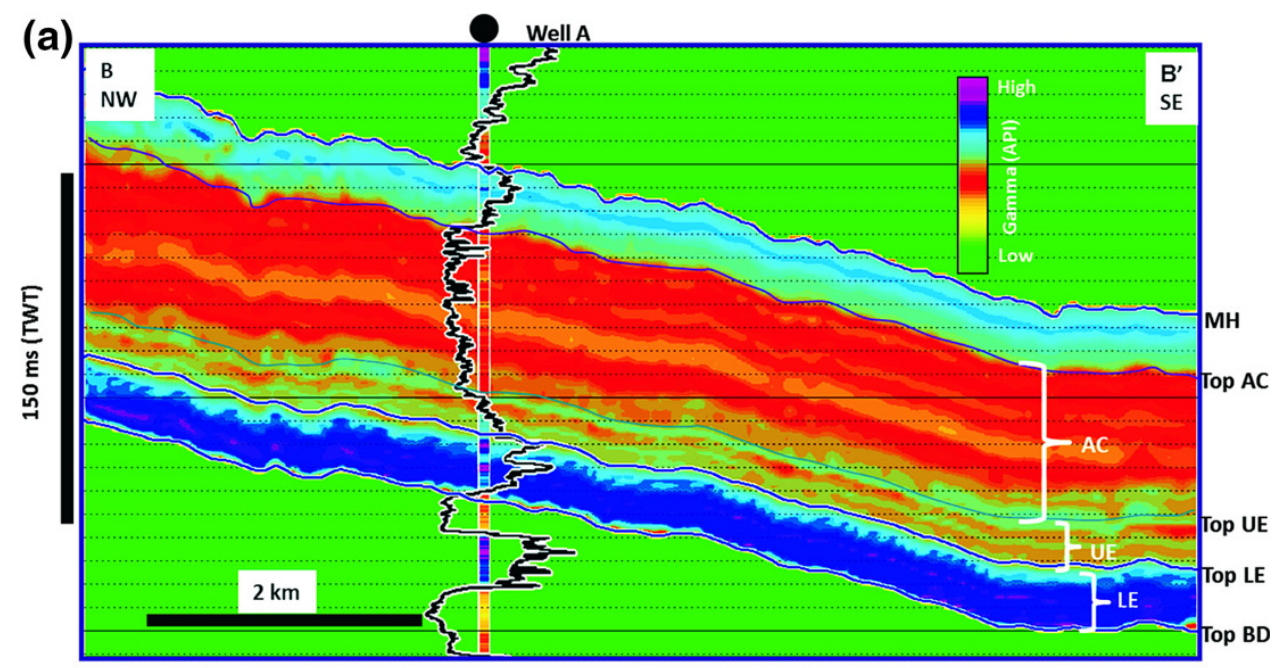

(b)

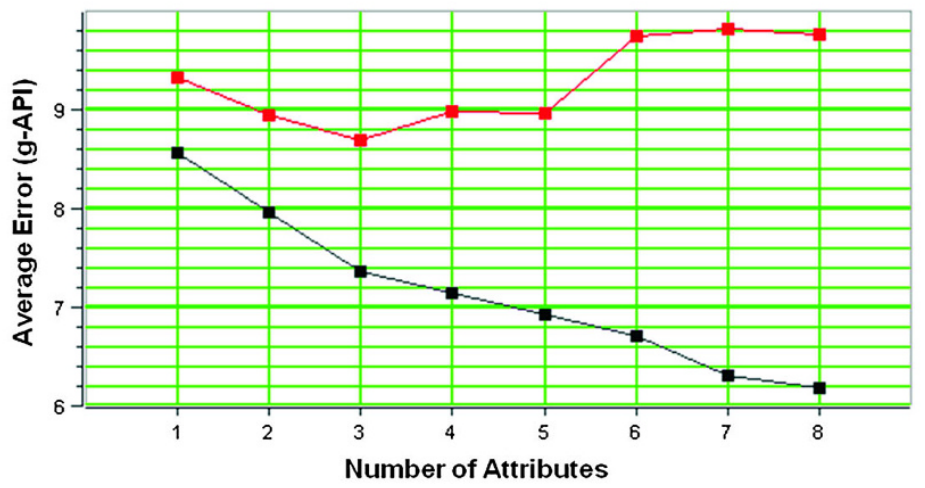

(c)

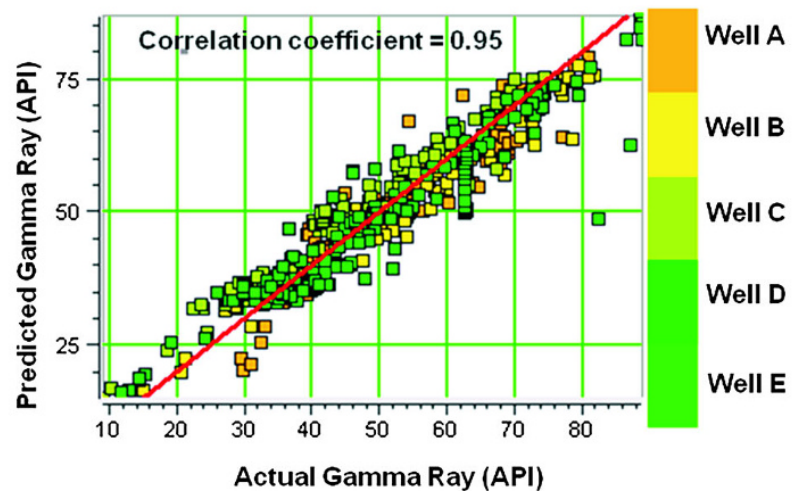

\#5, the difference between the error and attribute \#5 is insignificant. Therefore, we used three attributes in the prediction.

To invert for resistivity (deep induction log, ILD) and TOC, we input gamma-ray and AI volumes, serving as external attributes, into the multiattribue analysis package, together with other poststack-derived seismic attributes. Relevant attributes to predict TOC and ILD were also selected by the multiattribute analysis algorithm. Lateral variation of resistivity is shown along transect B-B' (Fig. 8a), and a combination of four attributes is clearly optimal for prediction of ILD (Fig. 8b) having a correlation coefficient of 0.98 (Fig. 8c). Although the error starts to decrease again at attribute $\# 5$, the difference between attribute \#4 and \#5 is huge and far more significant compared to that at attribute \#5. Therefore, instead of using all the attributes, which would have led to overprediction, we chose four attributes for prediction of resistivity. The vertical distribution of TOC can be seen along transect B-B' (Fig. 9a). Additionally, a combination of four attributes was also sufficient to predict this property with a high correlation coefficient of 0.98 (Fig. 9b, c). Note the absence of difference in average error between the fourth and fifth attributes (Fig. 9b). Because the point at which the 
Fig. 8 Results from resistivity (deep induction, ILD) inversion showing a ILD distribution along transect B-B' and b plot of average error versus number of attributes. Optimal number of attributes to predict ILD is four. Note big difference in average error between first and second attributes compared with small differences associated with remaining two attributes. Note that black curve indicates error using all wells, whereas red curve shows error plot when one well is removed. c Cross plot of predicted versus original ILD showing high degree of correlation

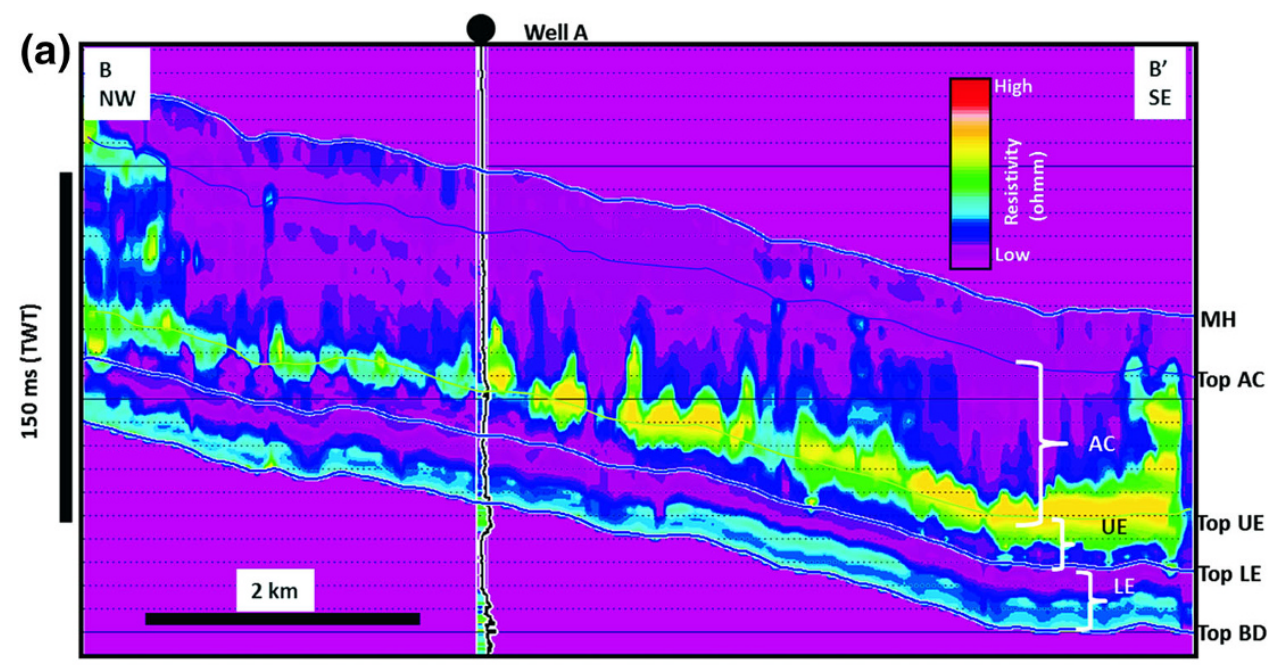

(b)

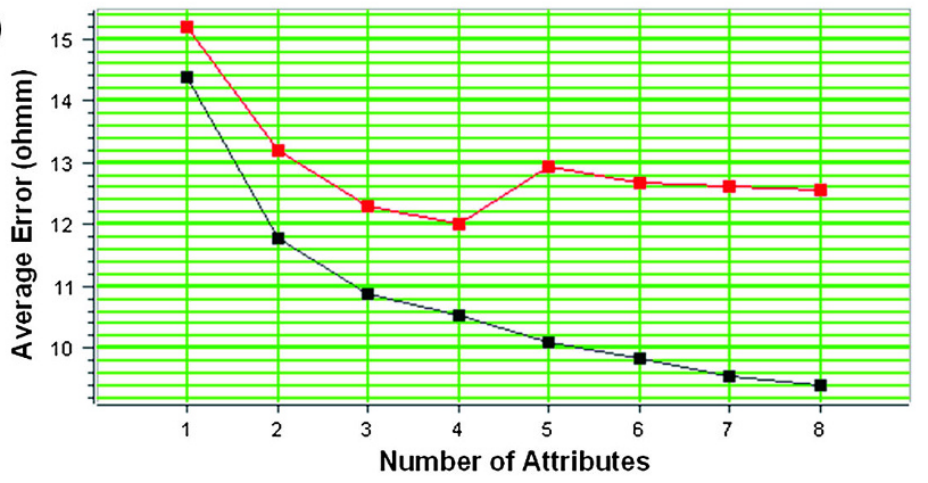

(c)

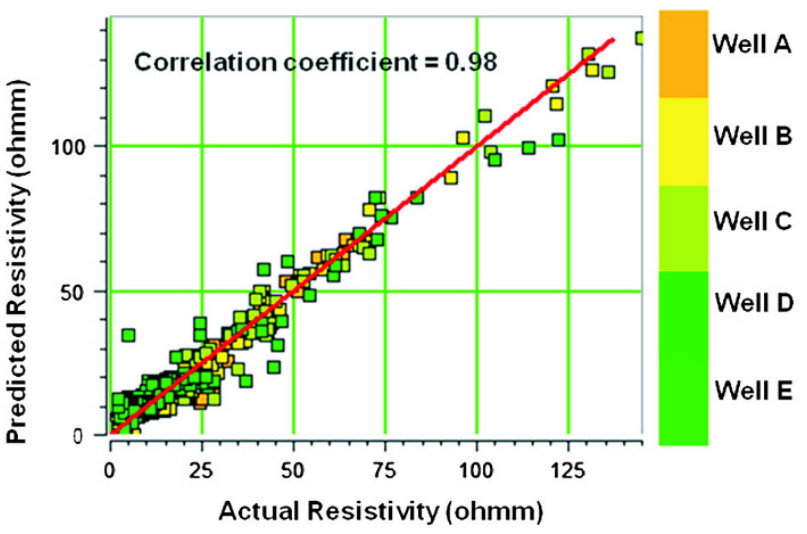

average error stops decreasing occurs at the fourth attribute, four attributes must be used to predict TOC.

Note the similarity in vertical distribution of ILD and TOC (Figs. 8, 9, respectively). Note also the almost continuous nature of ILD and TOC within the upper and lower Eagle Ford intervals south of Well A. The ILD and TOC maps extracted at $2 \mathrm{~m}$ below the top Eagle Ford horizon (Fig. 10a, b) show the lateral distribution of TOC and ILD, respectively. On these maps, a maximum concentration of both properties lies to the south and southwest of the survey area. In the south half of the survey, ILD and TOC distribution appears to be more continuous than it is in the north. In addition, note the similarity between the lateral distribution of ILD and TOC. High-ILD zones correspond to high-TOC zones. Areas of low TOC and low ILD (lightgreen zones in both cases) are major fault zones, as confirmed by the superposition of some fault traces from the coherency map (Fig. 10c) on top of the ILD and TOC maps. Coherency attributes were also extracted at about $12 \mathrm{~m}$ below the top lower Eagle Ford (Fig. 11a). As can be seen on this map, fault trends are mostly NE-SW, and numerous small faults are present. Although some of these 
Fig. 9 Results from total organic carbon (TOC) prediction showing a TOC distribution along transect B-B' and $\mathbf{b}$ plot of average error versus number of attributes; note absence of difference in error between fourth and fifth attributes. Therefore we conclude that optimal number of attributes is four. Note that black curve indicates the error using all wells, whereas red curve shows the error plot when one well is removed. c Cross plot of derived TOC and predicted TOC showing high correlation coefficient of 0.98
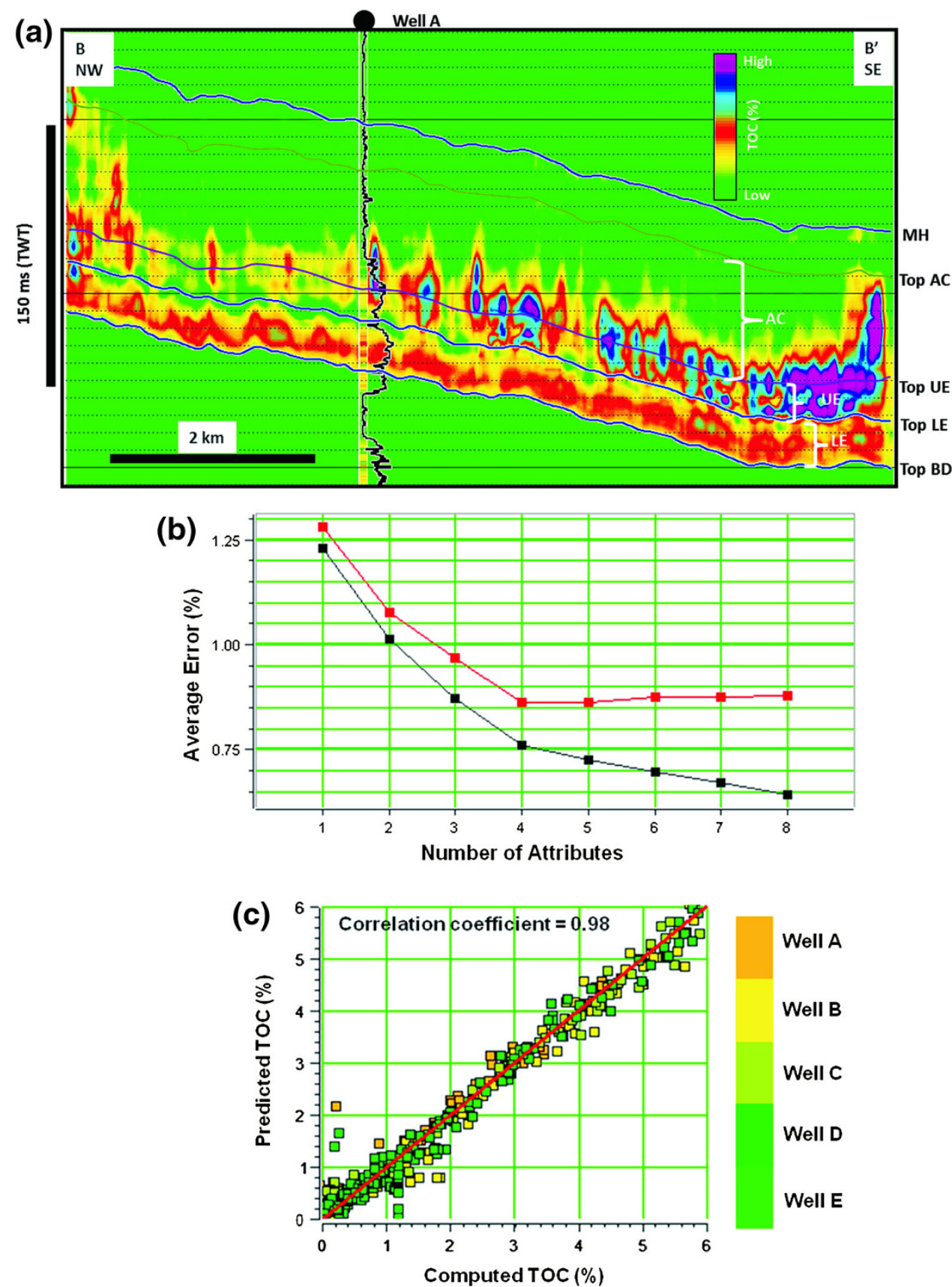

Well A

Well B

Well C

Well D

Well E

small faults are seen in the north, they are concentrated mostly in the south part of the survey. Superposition of major fault traces on top of the TOC map at this horizon (Fig. 11b) shows that the faults tend to occur in areas of low TOC (green areas). Note the area of high TOC concentration within the black dotted line to the south.

The optimal number of attributes in each multiattribue analysis process is tabulated vertically in order of importance (Table 1). The first most significant attribute to predict gamma ray (lithology) is the inverse of the acoustic impedance (1/AI). The other two attributes are narrowband frequency filters, which can be thought of as one in that both are low-frequency filters, suggesting the dominance of low-frequency zones within the interval of investigation. The low frequencies within the interval could be caused by the presence of faults, fractures, hydrocarbon zones, and some shale-rich zones. Essentially two attributes are therefore used to predict lithology-low-frequency attribute and 1/AI. Of these, 1/AI is the primary attribute, with a correlation coefficient of 0.82 , higher than the coefficients of the other two attributes (Table 1). Similarly, the four attributes used to predict resistivity (ILD) can be grouped into (1) amplitude-related and (2) frequency-related attributes. Frequency-related attributes 


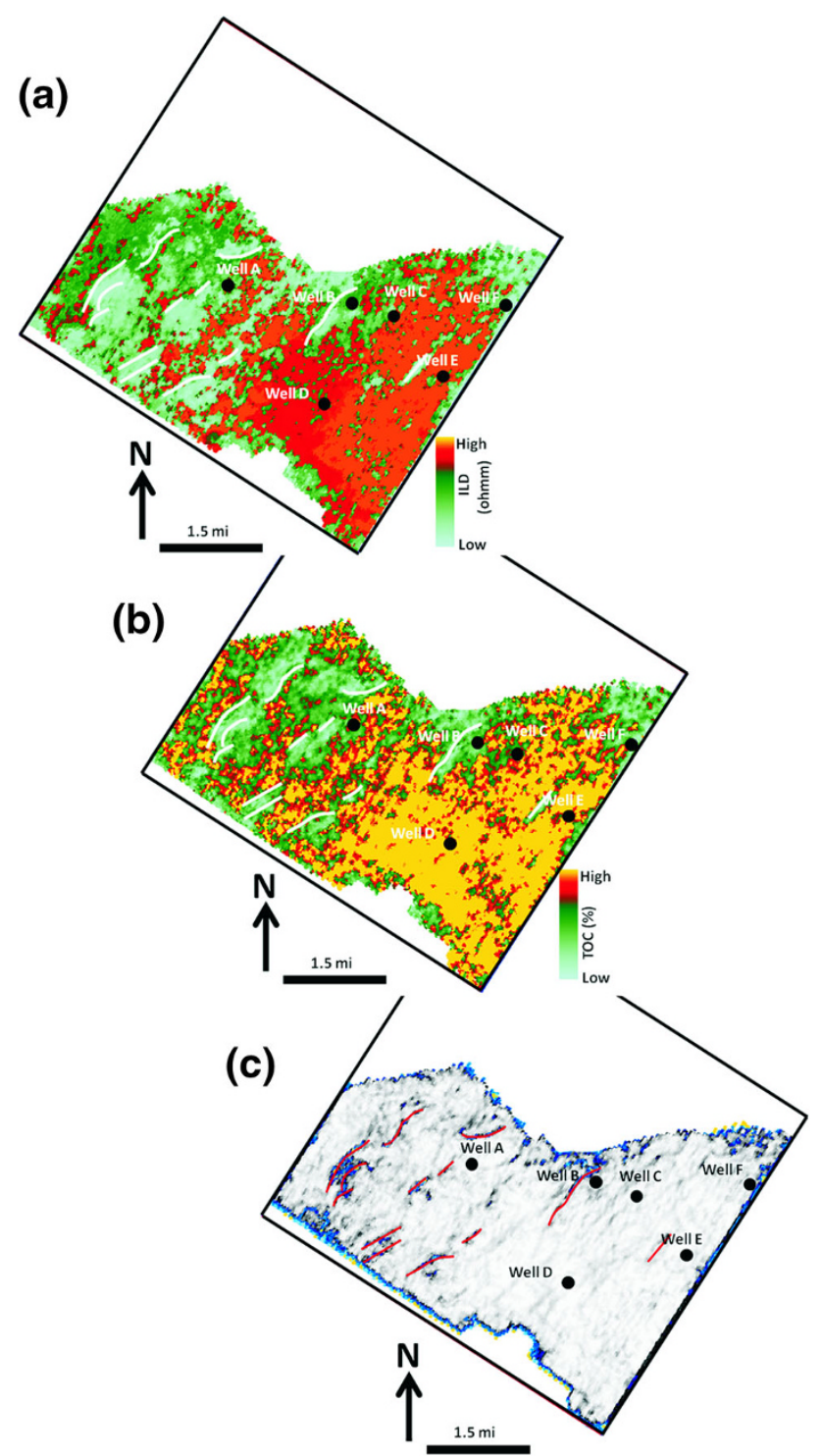

Fig. 10 Inversion results showing lateral-distribution maps of predicted properties extracted along horizon phantomed $2 \mathrm{~m}$ below top upper Eagle Ford: a resistivity (ILD) map and $\mathbf{b}$ total organic carbon (TOC) map. c Coherency map also generated along same horizon. Fault traces, red in c, superimposed on ILD and TOC maps; fault traces shown by white lines in both $\mathbf{a}$ and $\mathbf{b}$

(average frequency and filter 15-20-25-30) are both lowfrequency attributes, again suggesting the low-frequency composition of the zone of investigation as seen in lithology prediction. The quality attribute is both amplitude and frequency related. Either way, the square of the instantaneous quality factor $\left(Q^{2}\right)$ is the most significant attribute to predict resistivity. It has a correlation coefficient of 0.73 , whereas the other attributes have lower correlations (Table 1). That $Q^{2}$ plays a major role can be seen from the plot of average error versus number of attributes (Fig. 8c), in which the difference between $Q^{2}$ and the second-mostsignificant attribute is larger (2.0) than the small

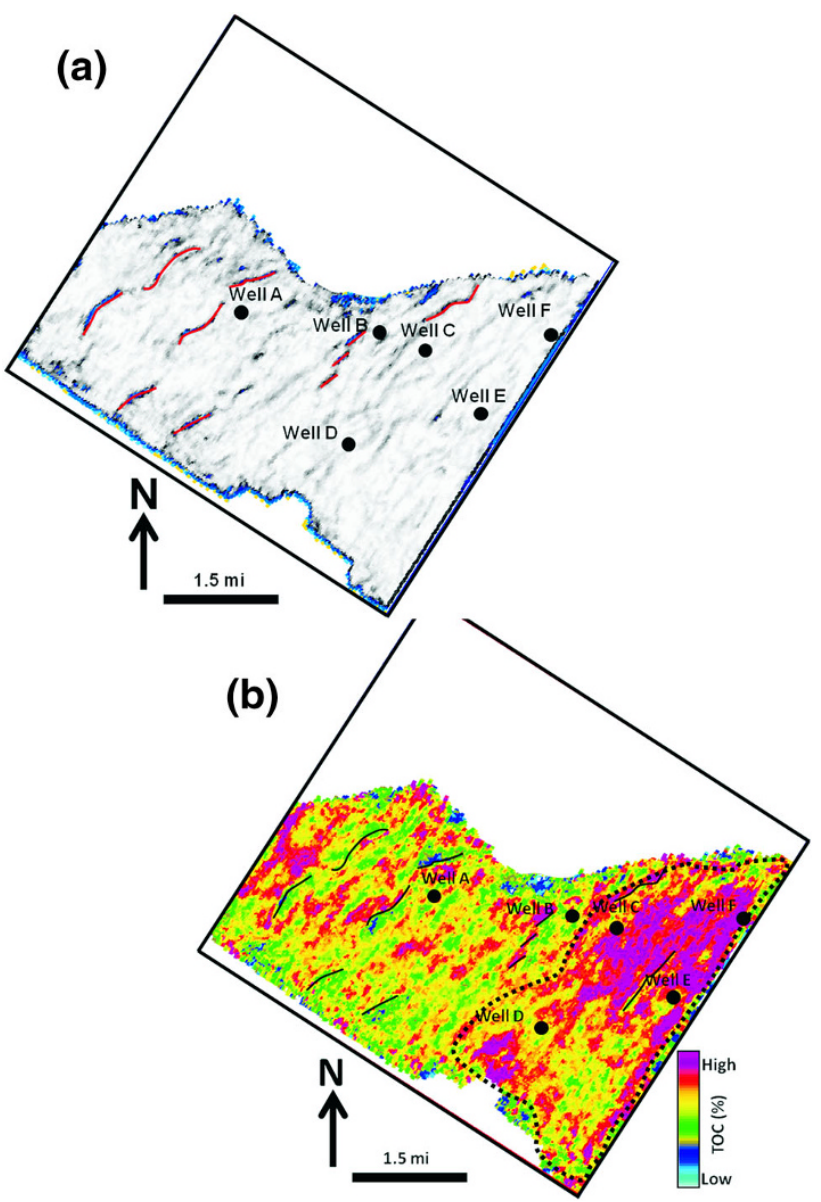

Fig. 11 Major fault traces extracted along horizon phantomed $12 \mathrm{~m}$ below top lower Eagle Ford: a coherency map; note fault traces in red. b Total organic carbon (TOC) map at same horizon. Black lines fault traces from coherency map. Note concentration of high TOC values (black dotted outline) in south half of survey area. Fault traces in TOC map occur in low-TOC zones (light-green and blue zones)

differences (1.0 and 0.2) between the other attributes. Like resistivity, four attributes were found to be optimal in the prediction of TOC. Apart from gamma ray $^{2}$, the other three attributes are amplitude related; as such, they can be grouped into (1) amplitude-related attributes $\left(Q^{2}\right.$, derivative of seismic trace, and amplitude-weighted cosine of phase) and (2) gamma ray $^{2}$. It is important to note that gamma ray $^{2}$ was chosen by the algorithm because it gave the best linear relationship between gamma ray and TOC (see further explanation under the Discussion section). Although gamma ray was not the primary attribute for predicting TOC, the relationship between lithology (gamma ray) and TOC has been discussed by several authors (e.g., Sondergeld et al. 2010). These authors noted that high-gamma-ray intensity is recorded on wireline logs in zones having anomalously high uranium content in organic matter (TOC). However, high gamma ray response does not necessarily suggest high TOC; for example, in this 
study, where gamma ray is highest, the corresponding TOC is low (Fig. 5). Because associated AI value is low, we conclude that identified high-gamma-ray zone is shale. Of the amplitude-related attributes, $Q^{2}$ was also found to be the most significant attribute, with a correlation coefficient of 0.64 , higher than correlation coefficients of the other three attributes (Table 1).

\section{Discussion}

In this section we focus on the instantaneous quality factor $(Q)$, resistivity (ILD), and acoustic impedance (AI). When the pore spaces within a resistant rock are filled with fluids, calculated $Q$ within the pores are low, whether the fluids are hydrocarbons or brine. However, the corresponding resistivity is high if the fluids are hydrocarbons, but low if the fluid is brine. Note that the resistivity in this case is not caused by the matrix but by the fluid; however, for the matrix, which constitutes the brittle part of the rock, resistivity is high and $Q$ is also high. Note that low $Q$ is an indication of porosity (Ogiesoba 2010), and the degree of porosity determines the values of $Q$. That is, $Q$ decreases as porosity increases (Ogiesoba and Eastwood 2013).

In the case of entirely organic-rich shale, resistivity is high, but $Q$ is low; in this situation, there is no brittle zone. However, shales are not stratigraphically or spatially homogeneous (Slatt and Abousleiman 2011). They contain some fine-grained sandstone and sometimes carbonate materials that can be more resistant than the encasing shales. In this case, the more resistant rock materials would have relatively higher $Q$ than would the encasing rock. This is the case with the Eagle Ford Shale. The shale contains about $45-64 \%$ carbonate, $13 \%$ quartz, and $27 \%$ clay minerals (Hildred et al. 2011; Sondhi 2011; Slatt et al. 2012). Based on the mineralogical composition, it becomes obvious why the $Q$ attribute can be an effective discriminating tool in identifying brittle zones within the Eagle Ford Shale. The carbonate intervals are more resistive and thus, having higher $Q$ than the encasing shale, they act as the brittle zones. A comparison of $Q$ and resistivity transects (Fig. 12a, b; transect C-C') shows a good correlation between $Q$ and resistivity.

During the prediction process, the square of the quality factor, $Q^{2}$, was used to predict the deep induction $\log$ (ILD). The choice of $Q^{2}$ is based on the following explanation. Because the prediction algorithm makes use of the linear relationship between log property and attributes, if the cross plot shows nonlinearity, the algorithm tests for linear relationships using nonlinear transforms. For example, if the cross plot between a target log and an attribute resembles a curve, the algorithm will test different nonlinear transforms such as log, square, square root, etc., to see whether a linear relationship is created by any of the transforms. From these tests, the transform that creates the best linear relationship is chosen. In our case, $Q^{2}$ was found to provide the best linear relationship between ILD and $Q$ (Fig. 12c), suggesting that the relationship between ILD and $Q$ is nonlinear. We therefore used $Q^{2}$ in the prediction process instead of $Q$. The interval having the highest resistivity (i.e., highest $Q$ values) is the upper Eagle Ford (Fig. 12).

The reason $Q^{2}$ is the primary attribute for predicting TOC can be found in the equation used in TOC computation (Passey et al. 1990):

$\operatorname{TOC}(\mathrm{wt} \%)=\Delta \log R 10^{(2.297-0.1688 \text { LOM })}$,

where $\Delta \log R$ is the separation between the sonic $\log$ (DT) and resistivity (ILD) (Fig. 5). This separation in the context of $\Delta \log R$ implies that the scale of the resistivity $\log$ is a 4-decade logarithmic scale and that of the sonic $\log$ is a $200 \mu \mathrm{s} / \mathrm{ft}$ difference. The separation is then digitally measured and input into the algorithm to compute $\Delta \log R$. LOM (level of organic maturity) is a fixed value; LOM ranges from 0 to 20 (Passey et al. 2010). In this study, LOM was assigned the value of 9 because the maturity of the Eagle Ford source rock in the study area places it in the oil window according to the calculated $R_{\mathrm{o}}$ value $\left(R_{\mathrm{o}}=0.7\right) . R_{\mathrm{o}}$ is the source maturity measured from vitrinite reflectance; a $R_{\mathrm{o}}$ value from 0.5 to 0.8 indicates oil-prone source rock; $\Delta \log R$ was computed from Eq. 1 of Passey et al. (1990). In Eq. 5, the only

Table 1 Selected optimal number of attributes in each prediction process arranged in order of importance with the corresponding correlation coefficients

\begin{tabular}{|c|c|c|}
\hline Gamma ray (Lithology) & Resistivity (ILD) & TOC \\
\hline $\begin{array}{l}1 /(\text { acoustic impedance }) \text { correlation } \\
\text { coefficient }=0.82\end{array}$ & $\begin{array}{l}\text { (Quality factor) })^{2} \text { correlation } \\
\text { coefficient }=0.73\end{array}$ & $(\text { Quality factor })^{2}$ correlation coefficient $=0.64$ \\
\hline $\begin{array}{l}\text { Filter } 15 / 20-25 / 30 \text { correlation } \\
\text { coefficient }=0.08\end{array}$ & $\begin{array}{l}\text { Average frequency correlation } \\
\text { coefficient }=0.47\end{array}$ & Gamma ray $^{2}$ correlation coefficient $=0.47$ \\
\hline \multirow[t]{2}{*}{$\begin{array}{l}\text { Filter } 5 / 10-15 / 20 \text { correlation } \\
\text { coefficient }=0.07\end{array}$} & Derivative correlation coefficient $=0.42$ & $\begin{array}{l}\text { Derivative instantaneous amplitude correlation } \\
\text { coefficient }=0.31\end{array}$ \\
\hline & $\begin{array}{l}\text { Filter } 15 / 20-25 / 30 \text { correlation } \\
\text { coefficient }=0.19\end{array}$ & $\begin{array}{l}\text { Amplitude-weighted cosine phase correlation } \\
\text { coefficient }=0.09\end{array}$ \\
\hline
\end{tabular}


Fig. 12 Comparison of resistivity (ILD) with quality factor $(Q)$ along transect $\mathrm{C}-\mathrm{C}^{\prime}$ : a ILD transect and $\mathbf{b} Q$ transect. Note inserted ILD curve (black) for Well E in both figures; highest resistivity values in a occur in zone of highest $Q$ in b (white ellipses). White dotted vertical lines connect corresponding ILD and $Q$. c Plot of $Q^{2}$ versus ILD showing linear relationship between both properties-increasing $Q$ suggests increasing resistivity. $L R B$ lower resistive bed, $U R B$ upper resistive bed
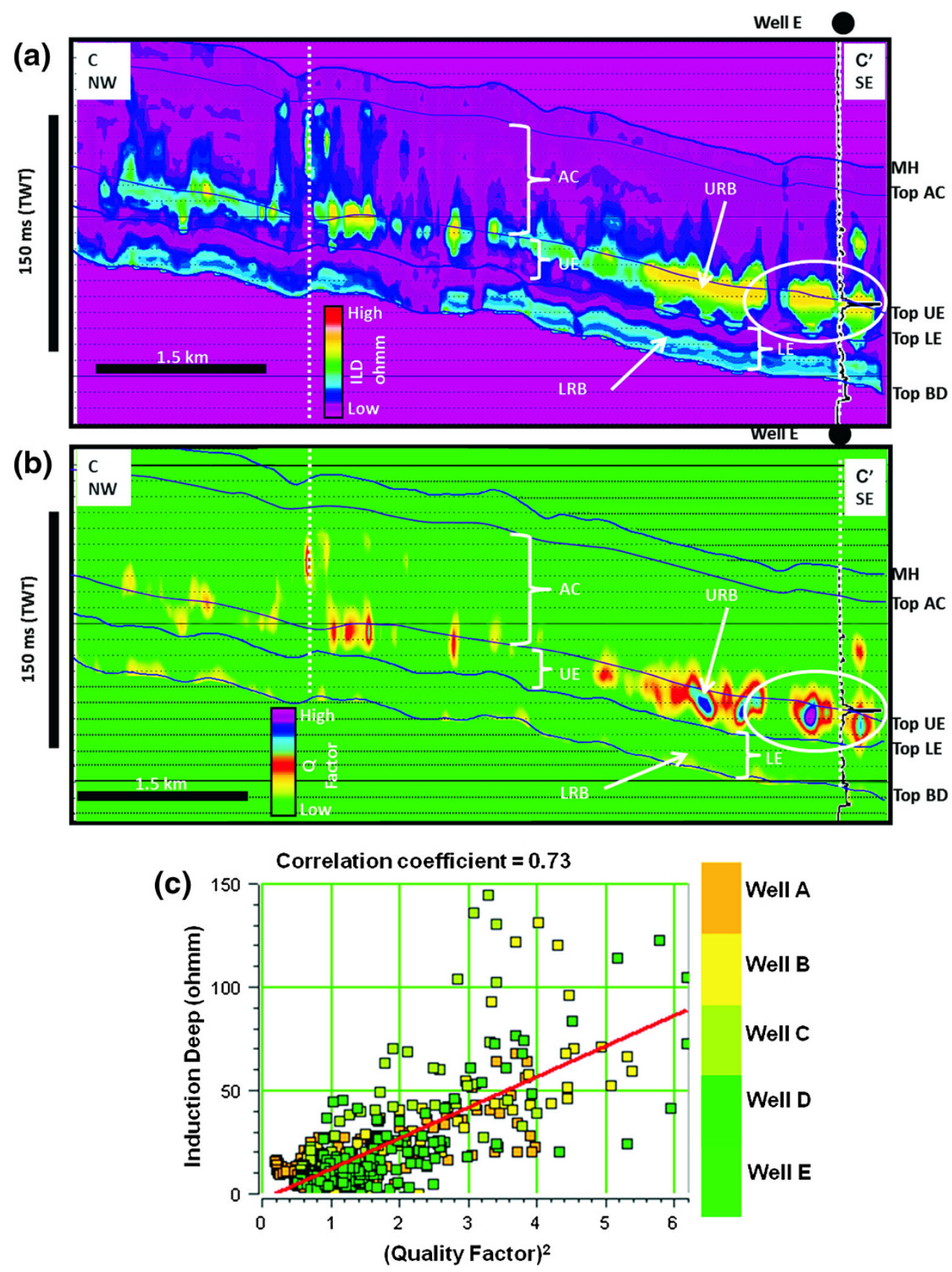

variable to determine TOC is $\Delta \log R$ multiplied by a constant. Because of the dependence of TOC computation on ILD, the computed TOC $\log$ motif is similar to that of ILD (Fig. 5), and the most significant attribute for predicting TOC is also $Q^{2}$. Because high $Q$ valueswhich are indicative of less absorptive, or brittle, rocks correlate with high resistivity values, the observed high ILD values might have had some contribution from the resistant bed. That is, the high ILD values are not entirely due to the TOC or hydrocarbon effect but are instead a combination of TOC or hydrocarbon and resistant lithology.
Physically, $Q$ has no relationship with TOC other than the fact that its values are lower in a rock that is TOC-rich than would be the $Q$ values observed in the same rock type that is devoid of TOC. However, studies of some Eagle Ford cored wells (Sondhi 2011) showed that TOC increases as the carbonate content increases, whereas TOC decreases as the clay content increases. Because TOC increases with increasing carbonate content, high $Q$, which suggests a high percentage of carbonate, would also suggest high TOC. This characteristic means that high resistivity also suggests high TOC, because high $Q$ suggests high resistivity. As can be seen from Figs. 7a, 8a, high resistivity 


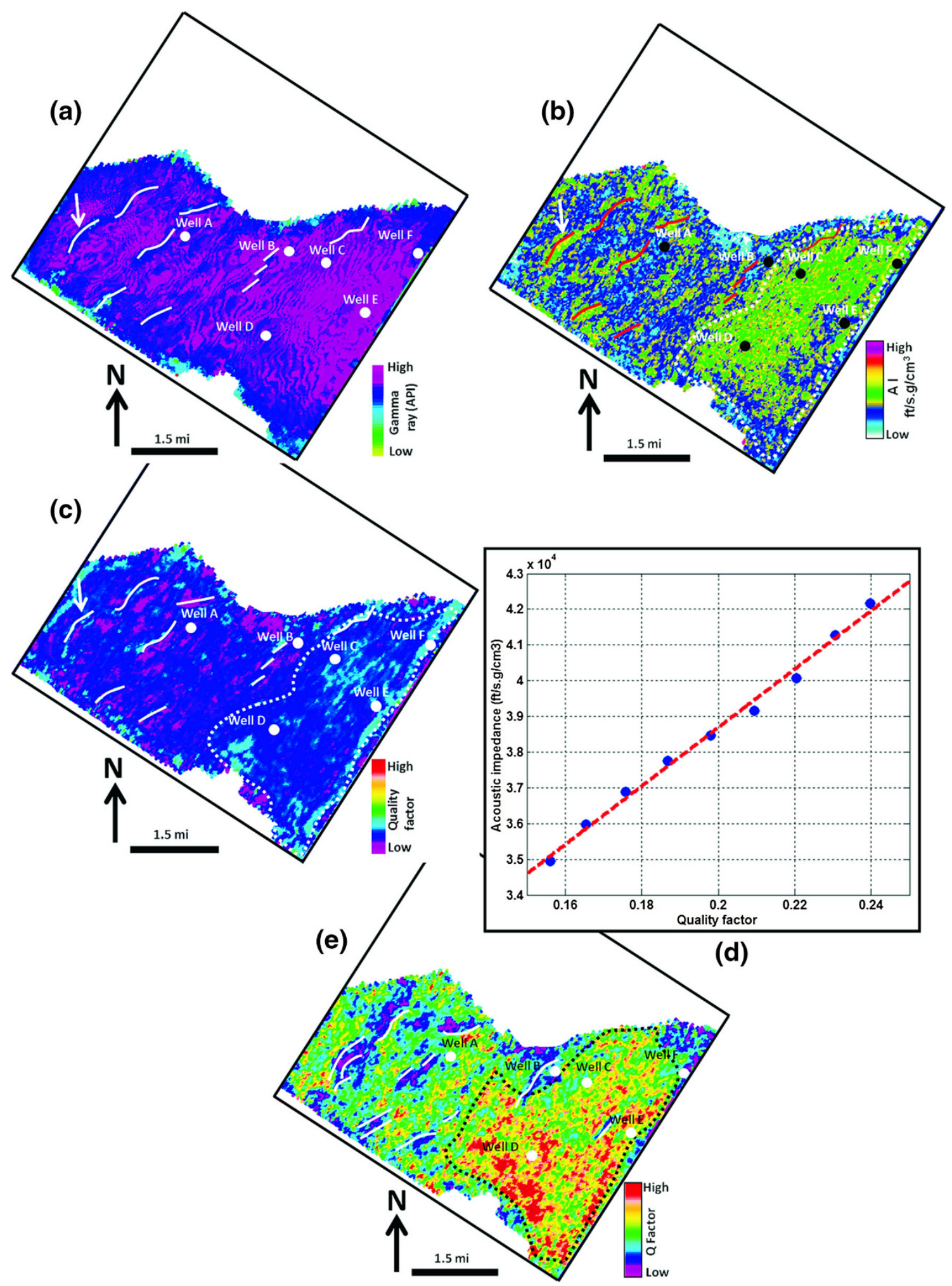

corresponds to high TOC; and from Fig. 12a, high $Q$ corresponds to high resistivity. Hence high $Q$ corresponds to high TOC. In addition, within the lower Eagle Ford Shale $Q$ is low, resistivity is low, and TOC is also low (Figs. 7a, 8a, 12a), suggesting increasing clay content. We would like to emphasize that high $Q$ corresponds with resistant beds (the brittle zones) which are, in this case, carbonate- and TOC-rich beds. Because of the strong correlation between 
4 Fig. 13 Extracted attribute maps along horizon phantomed $12 \mathrm{~m}$ below top lower Eagle Ford showing a gamma-ray map, b acoustic impedance (AI) map, and c quality factor $(Q)$ map. Note on gammaray map, horizon characterized throughout by high gamma ray (magenta) except in fault zones where low-gamma-ray values are seen (blue and cyan). White lines fault traces from coherency. Note also almost identical display of $\mathrm{AI}$ and $Q$ maps, suggesting relationship between $\mathrm{AI}$ and $Q$. White dotted outlines in both $\mathrm{AI}$ and $Q$ maps, representing areas of high $\mathrm{AI}$ and $Q$, respectively, are almost same. Red traces in $\mathrm{AI}$ and white traces in $Q$ maps fault traces from corresponding coherency map. d Cross plot of AI versus $Q$ in interval containing mapped horizon, showing that relationship between AI and $Q$ is linear. e $Q$ attribute map extracted along horizon phantomed $2 \mathrm{~m}$ below upper Eagle Ford, showing area of highest $Q$ values (black dotted outline). Dotted outlines in $\mathbf{b}$ (white), c (white), and e (black) are most brittle zones (see text for details)

TOC and carbonate (Sondhi 2011), $Q$ was chosen by the multiattribute algorithm as the best attribute to predict TOC. Herein lies the relationship between $Q$ and TOCTOC increases as $Q$ increases (Figs. 7a, 8a, 12a). The Eagle Ford Shale is therefore a unique shale-a calcareous marl, in which the TOC content increases with increasing bed resistance. We consider the high-resistant bed a possible barrier to upward hydrocarbon migration in that it could act as a cap rock in some cases, not only trapping hydrocarbons generated within it because it is rich in TOC but also trapping hydrocarbons generated within the TOCrich lower Eagle Ford, particularly where the bed is more continuous. If the bed were fractured or faulted, trapped hydrocarbons would escape and migrate into the overlying
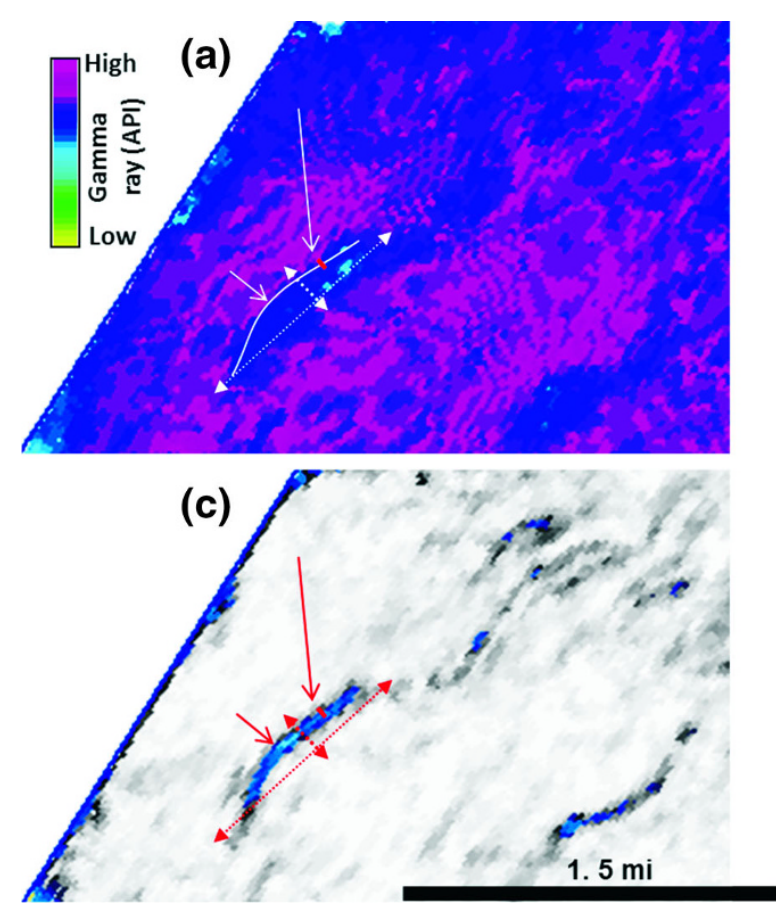

Fig. 14 Enlarged version of parts of Figs. 11a, 13a-c, showing fault zone encased within carbonate-rich (brittle) rock: a gamma ray map, b AI map, c coherency map, and $\mathbf{d} Q$ attribute map. Note short arrow
Austin Chalk. Thus, we interpret the sweet spots within the Eagle Ford Shale to lie directly beneath and within the resistant (high- $Q$ ) beds.

Two such beds/intervals occur within the Eagle Ford Shale in the Maverick Basin: (1) the upper resistant bed (URB) just below the top of the upper Eagle Ford and (2) the lower resistant bed (LRB) within the lower Eagle Ford (Fig. 12a, b). The LRB is thinner, at approximately $\sim 30-95 \mathrm{ft}(9-29 \mathrm{~m})$, than the URB, which is about $\sim 68-270 \mathrm{ft}(21-82 \mathrm{~m})$ thick. Although the lower Eagle Ford is generally composed of high gamma-ray values (Fig. 13a), the LRB within it exhibits some relatively high AI and $Q$ values, suggesting that the LRB could be more calcareous and, therefore, more brittle than the surrounding shale matrix. A comparison of $\mathrm{AI}$ and $Q$ attribute maps (Fig. 13b, c) shows that both $Q$ and AI yield similar results: high-AI and high- $Q$ areas are almost identical in both maps. For example, the areas outlined by the white dotted line in the south part of the survey have similar shapes.

Cross plots of AI and $Q$ attributes obtained from the lower Eagle Ford at Well D (Fig. 13d) show a good linear relationship between the two attributes-that is, $Q$ increases with increasing AI. Because high AI suggests a high elastic modulus, it follows that high $Q$ also suggests a high elastic modulus, suggesting increasing brittleness. Therefore, $Q$ attributes can be used to identify brittle zones within the Eagle Ford Shale. Because the $Q$ attribute is faster and cheaper to compute from 3D poststack seismic

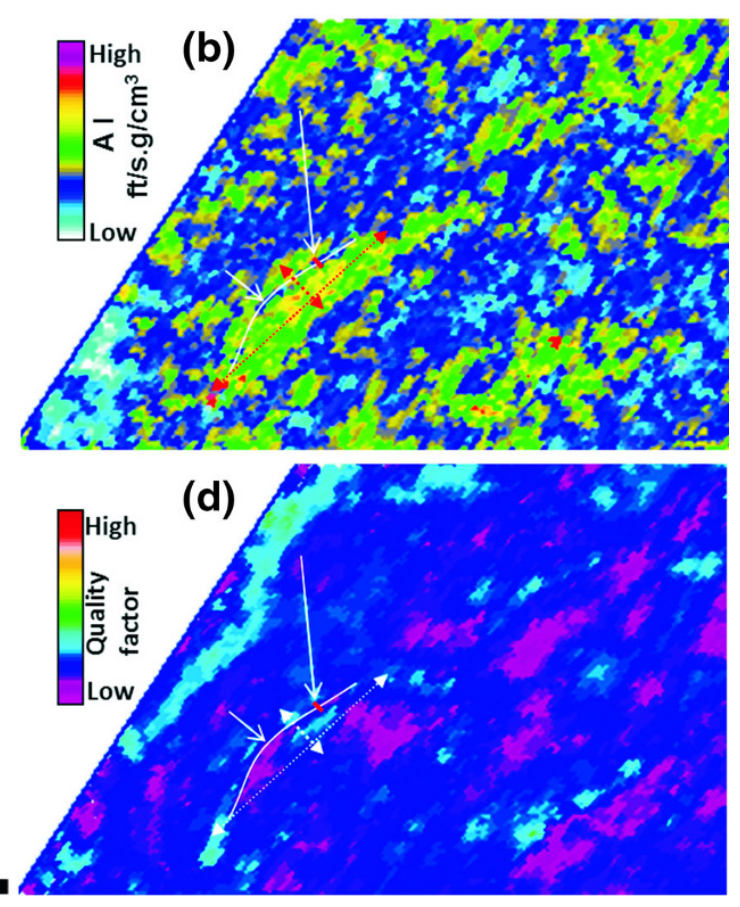

points to fault zone and long arrow points to width of fault zone indicated by red short bar in all four figures

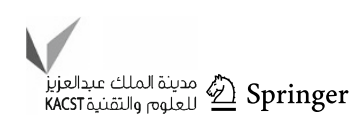


data than other attributes, it could offer the fastest and cheapest method of identifying brittle zones within the Eagle Ford Shale and could assist explorationists in planning horizontal wells. A $Q$ attribute map extracted within the URB shows brittle zones (Fig. 13e), and $Q$ values in this interval are higher than those within the LRB. As can be seen on the URB map (Fig. 13e), although the most brittle zones (higher $Q$ ) are in the southeast half of the survey, the entire map area appears to be composed of relatively high $Q$. Areas of low $Q$ (magenta) correspond to fault zones. In contrast, within the LRB, the most brittle zones are concentrated mostly in the southeast part of the map (Fig. 13c). Few relatively high $Q$ zones, which are linear and trend NE-SW, can be seen in the north half of the survey area. These same linear trends can also be seen in the AI map (Fig. 13b). What Fig. 13b, c suggest is that the rock units in which the faults occur are composed of more brittle (carbonate) materials than the surrounding matrix (predominantly shale). However, areas occupied by the fault traces (i.e., fault zones) have lower $Q$ and lower AI compared to the carbonate rock unit that contains the fault zones. For example, consider the linear feature indicated by white arrows in Fig. 13b and c; an enlarged version of it (Fig. 14) shows that it is $\sim 0.96 \mathrm{mi}(\sim 1.54 \mathrm{~km})$ long (northeast-trending double-headed arrow) and $1,373 \mathrm{ft}$ ( $\sim 418 \mathrm{~m})$ wide (southeast-trending double-headed arrow). The fault zone (thin white line indicated by short arrow, Fig. 14a-d) contained by this feature is $\sim 200-300 \mathrm{ft}$ ( $\sim 61-91 \mathrm{~m})$ wide and is characterized by lower $Q$ and lower AI than exhibited by the rest of this rock unit.

\section{Conclusions}

In studying the lateral and vertical distribution of TOC and resistivity within the Eagle Ford Shale by analyzing seismic attributes, including $\mathrm{AI}$ and well logs, we found that the upper Eagle Ford Shale interval has higher AI values than the lower Eagle Ford Shale because it is more calcareous. Both the upper and the lower Eagle Ford Shale intervals are TOC rich. Horizon slices show that high-TOC and high-resistivity zones are concentrated mostly in the south and southwest parts of the survey and are laterally more continuous there. In the north half of the survey, continuity of these properties is broken by NW-SE-trending faults having throws ranging from 10 to $100 \mathrm{ft}$ $(\sim 3-30 \mathrm{~m})$. The high-resistivity and high-TOC zones correlate strongly with high $Q$, an attribute that indicates absorption characteristics and the relative Young's modulus of the beds. Two high-resistivity zones, an upper resistive bed and a lower resistive bed, are identified within the Eagle Ford Shale in the study area. Although both beds exhibit high resistivity, the upper bed is characterized by higher resistivity values. Because high-resistivity zones correlate strongly with the high $Q$ attribute, and because the zones are associated with high TOC, the high resistivity values are interpreted to be a combination of resistivity due to TOC and resistant lithology. Additionally, because the $Q$ attribute relates to the Young's modulus of the rock and also correlates with AI, it can be used to identify brittle zones. Furthermore, because $Q$ is faster and cheaper to compute from the 3D poststack seismic data set than AVO prestack attributes, it could serve as a quicker, alternate method of identifying brittle zones within the Eagle Ford Shale.

Acknowledgments We thank our industry partner, Boilingstone Exploration, for supplying the data. We also thank the Landmark University Program and Hampson and Russell for supplying the software used in this study. We also thank Susie Doenges and Chris Parker for editing the manuscript and John Ames for preparing the figures. Publication authorized by the Director, Bureau of Economic Geology, The University of Texas at Austin.

Open Access This article is distributed under the terms of the Creative Commons Attribution License which permits any use, distribution, and reproduction in any medium, provided the original author(s) and the source are credited.

\section{References}

Baldwin OD, Adams JAS (1971) $\mathrm{K}^{40} / \mathrm{Ar}^{40}$ ages of the alkalic igneous rocks of the Balcones fault trend of Texas. Tex J Sci 22(2 and 3):223-231

Barnes A (1992) The calculation of instantaneous frequency and instantaneous bandwidth (shot note). Geophysics 57:1520-1524

Barnes A (1993) Instantaneous bandwidth and dominant frequency with applications to seismic reflection data. Geophysics 58:419-428

Dawson WC (2000) Shale microfacies: Eagle Ford Group (Cenomanian-Turonian) North-Central Texas outcrops and subsurface equivalents. Gulf Coast Assoc Geol Soc Trans 50:607-622

Donovan AD, Staerker TS (2010) Sequence stratigraphy of the Eagle Ford (Boquillas) Formation in the subsurface of South Texas and outcrops of West Texas. Gulf Coast Assoc Geol Soc Trans 60:861-899

Eastwood RL, Hammes U (2010) Log model development for the Bossier and Haynesville Shales. SPWLA 52nd annual logging symposium, pp 1-17

Ewing TE, Caran SC (1982) Late Cretaceous volcanism in south and central Texas-stratigraphic, structural, and seismic models. Gulf Coast Assoc Geol Soc Trans 32:137-145

Faust ILY (1953) A velocity function including lithologic variations. Geophysics 18:271-287

Goodway B, Chen T, Downton J (1998) AVO and prestack inversion. CSEG annual convention

Grabowski GJ Jr (1981) Source-rock potential of the Austin Chalk, Upper Cretaceous, Southeastern Texas. Gulf Coast Assoc Geol Soc Trans 31:105-113

Grant FS, West GF (1965) Interpretation theory in applied geophysics. McGraw-Hill, New York

Hamilton EL (1972a) A correlation between Qs of shear waves and rigidity. Mar Geol 13:27-30 
Hamilton EL (1972b) Compressional-wave attenuation in marine sediments. Geophysics 37:620-646

Hammes U, Hamlin HS, Ewing TE (2011) Geologic analyses of the Upper Jurassic Haynesville Shale in east Texas and west Louisiana. AAPG Bull 95(10):1643-1666

Hampson D, Schuelke J, Quirein J (2001) Use of multiattribute transform to predict log properties from seismic data. Geophysics 66:220-236

Hentz TF, Ruppel SC (2011) Regional lithostratigraphy of the Eagle Ford shale: Maverick Basin to East Texas Basin. Gulf Assoc Geol Soc Trans 60:325-337

Hildred G, Ratcliffe K, Schmidt K (2011) Application of inorganic whole-rock geochemistry to shale resource plays: an example from the Eagle Ford Shale, Texas. http://www.chemostrat.com/ wp-content/uploads/2013/08/Application-of-Inorganic-WholeRock-Geochemistry-to-Shale-Resource-Plays-an-Example-fromthe-Eagle-Ford-Shale-Texas.pdf. Accessed 17 Dec 2013

Hill RJ, Jarvie DM, Zumberge J, Henry M, Pollastro RM (2007) Oil and gas geochemistry and petroleum systems of the Fort Worth basin. AAPG Bull 91:445-473

IHS Energy Information (2012) https://penerdeq.ihsenergy.com/thin2/ secure/home/home.jsf. Accessed 16 Aug 2012

Johnston DH, Toksoz MN (1981) Seismic wave attenuation. Geophysics reprint series No. 2. In: Toksoz MN, Johnston DH (eds) Definitions and terminology., pp 1-5

Johnston DH, Toksoz MN, Timur A (1979) Attenuation of seismic waves in dry and saturated rocks: II. Mechanisms. Geophysics 44:691-711

Koesoemadinata A, El-Kaseeh G, Banik N, Dai J, Egan M, Gonzalez A, Tamulonis K (2011) Seismic reservoir characterization in Marcellus shale. Presented at San Antonio SEG annual meeting, $3700-3704$

Kuich N (1989) Seismic fracture identification and horizontal drilling: keys to optimizing productivity in fractured reservoir, Giddings field, Texas. Gulf Coast Assoc Geol Soc Trans 39:153-158

Laubach SE, Olson JE, Gross MR (2009) Mechanical and fracture stratigraphy. AAPG Bull 93(11):1413-1426

Lewis JO (1977) Stratigraphy and entrapment of hydrocarbons in the San Miguel sands of Southwest Texas. Gulf Coast Assoc Geol Soc Trans 27:90-98

Luttrell PE (1977) Carbonate diagenesis and facies distribution of the Anacacho Limestone associated with a Late Cretaceous volcano in Elaine Field, Dimmit County, Texas. Master's thesis, The University of Texas at Austin

Ogiesoba OC (2010) Porosity prediction from seismic attributes of the Ordovician Trenton-Black River groups, Rochester field, southern Ontario. AAPG Bull 94(11):1673-1693
Ogiesoba OC, Eastwood R (2013) Seismic multiattribute analysis for shale gas/oil within the Austin Chalk and Eagle Ford Shale in a submarine volcanic terrain, Maverick Basin, South Texas. Interpretation 1(2):61-83

Passey QR, Creaney S, Kulla JB, Maretti FJ, Stroud JD (1990) A practical model for organic richness from porosity and resistivity logs. AAPG Bull 74:1777-1794

Passey QR, Bahacs KM, Esch WL, Kimentidis R, Sinha S (2010) From oil-prone source rock to gas producing shale reservoirgeologic and petrophysical characterization of unconventional shale-gas reservoirs. Soc Pet Eng 13150:29

Rickman R, Mullen M, Petre E, Grieser B, Kundert D (2008) A practical use of shale petrophysics for stimulation design optimization: all shale plays are not clones of the Barnett Shale. SPE Paper No. 115258

Robinson EA, Treitel S (2008) Digital imaging and deconvolution: the $\mathrm{ABCs}$ of seismic exploration and processing. Geophysical references series No. 15. Society of Exploration Geophysicists, Hyderabad

Sena A, Castilo G, Chesser K, Voisey S, Estrada J, Carcuz J, Carmona E, Hodgkins P (2011) Seismic reservoir characterization in resource shale plays: stress analysis and sweet spot discrimination. Lead Edge 30:758-764

Slatt RM, Abousleiman Y (2011) Merging sequence stratigraphy and geomechanics for unconventional gas shales. Lead Edge 30(3):274-282

Slatt RM, O'Brien NR, Romero AM, Rodriguez HH (2012) Eagle Ford condense section and its oil and gas storage and flow potential. http://www.searchanddiscovery.com/documents/2012/ 80245slatt/ndx_slatt.pdf. Accessed 17 Dec 2013

Sondergeld CH, Newsham KE, Comisky JT, Rice MC, Rai CS (2010) Petrophysical considerations in evaluating and producing shale gas resources. SPE Paper No. 131768

Sondhi N (2011) Petophysical characterization of Eagle Ford Shale. Master Thesis, University of Oklahoma, Norman, Oklahoma, USA. http://mpge.ou.edu/research/documents/2011\%20thesis/ Namrita\%20Sondhi_thesis.pdf. Accessed 11 Dec 2013

Spencer AB (1969) Alkalic igneous rocks of the Balcones province, Texas. J Petrol 10(2):272-306

Toksoz MN, Johnston DH, Timur A (1979) Attenuation of seismic waves in dry saturated rocks: I. Laboratory measurements. Geophysics 44:681-690

Treadgold G, Campbell B, McLain B, Sinclair S, Nicklin D (2011) Eagle Ford shale prospecting with $3 \mathrm{D}$ seismic data within a tectonic and depositional framework. Lead Edge 30:48-53 